\title{
ANÁLISE ECONÔMICA DE DIFERENTES NIVEIS DE FÓSFORO NA PRODUÇÃO DE ARROZ CONSORCIADA COM BRACHIÁRIA EM SOLOS SOB VEGETAÇÃO DE CERRADO
}

MARIA INEZ ESPAGNOLI GERALDO MARTINS

Orientador: JOSÉ FERREIRA DE NORONHA

Dissertação apresentada à Escola Superior de Agricultura "Luiz de Queiroz", da Universidade de São Paulo, para obtenção do título de Mestre em Agronomia. Área de Concentração: Economia Agrária.

PIRACICABA

Estado de São Paulo - Brasil

Dezembro - 1983 
. II.

Aos meus pais, marido

e filho,

DEDICO . 


\section{AGRADECIMENTOS}

A Universidade Estadual Paulista "Jülio Mesquita Filho", "Campus" de Ilha Solteira e à Escola Superior de Agricultura "Luiz de Queiroz", pela oportunidade oferecida para rea lizar o curso de Pós-Graduação.

À CAPES, através do Programa Institucional de Capacitação de Do centes, PICD, pelá concessão da bolsa de estudos.

Ao Professor José Ferreira Noronha, pelo apoio e orientação.

Aos Professores Rodolfo Hoffmann e Evaristo Marzabal Neves, pelas criticas e sugestões.

Ao Dr. José Garcia Gasques, pelo constante apoio, incentivo e amizade.

Ao Engo Agro Antonio Joaquim Braga Pereira Braz, pelo inegável auxilio na fase de campo desse trabalho.

Finalmente, a todos os que, de alguma forma contribuiram para a realização deste trabalho. 


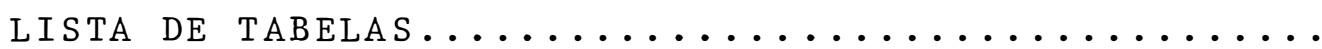

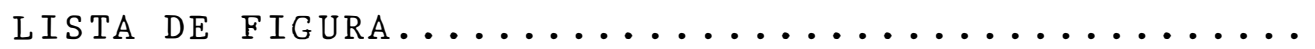

RESUMO .

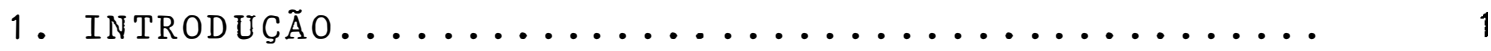

1.1. objetivos..................... 4

1.2. Organização do trabalho.............. 4

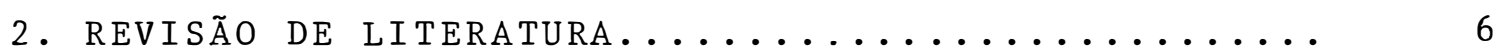

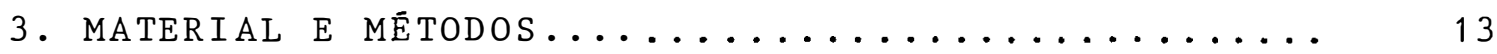

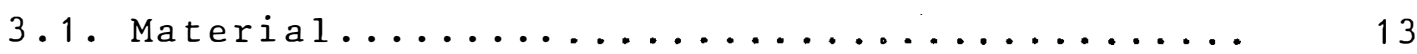

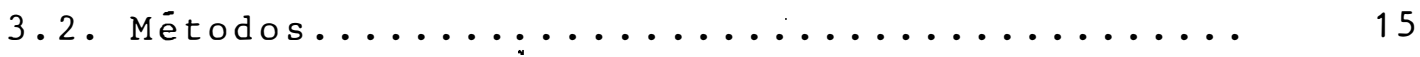

3.2.1. Modelo estatistico.............. 15

a) Equações estimadas............. 15

b) Testes das hipöteses.......... 17

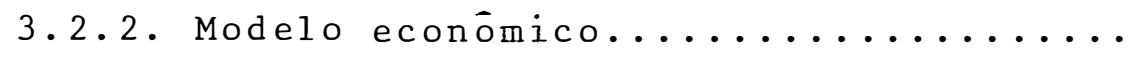

3.2.3. Modelo considerando os efeitos de blo cos e época de plantio da brachiária.

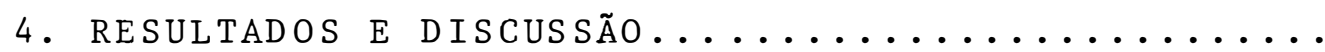

4. 1. Resultados descritivos................

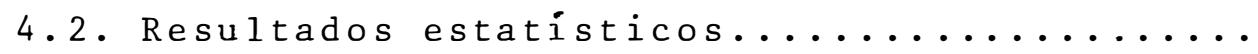

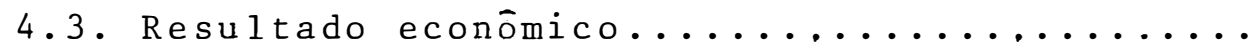


4.3.1. Dose ótima econômica...........

4.3.2. Demanda pelo insumo............

4.3.3. Anālise da variação dos preços.....

4.3.4. Determinação da melhor época de plan tio da brachiària..............

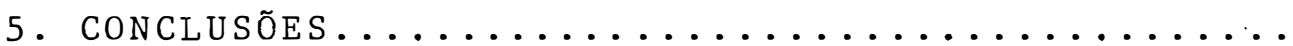

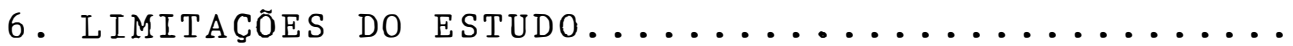

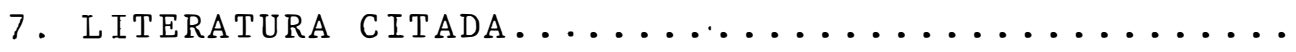
APÊNDICE. 


\section{LISTA DE TABELAS}

TABELA

Pägina

1 Tratamentos utilizados no experimento...

Estimativa do custo de aplicação de fósfo ro por hectare, ano de $1981 \ldots \ldots \ldots \ldots$

3 Rendimentos obtidos na cultura de arroz $\left(\mathrm{Y}_{\mathrm{A}}\right)$, por tratamento, nos diferentes expe rimentos (média quatro repetições) em kg/

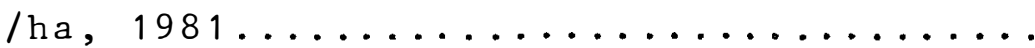

4 Rendimentos obtidos com a pastagem. $\left(\mathrm{Y}_{\mathrm{B}}\right)$, por tratamento nos diversos experimentos (média de quatro repetições), em $\mathrm{kg} / \mathrm{ha}$,

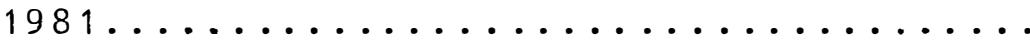

5 Estimativas dos parámetros da equação: $\bar{Y}=a+b x+c x^{2}$. Produção arroz, 1981...

6 Estimativas dos parāmetros da equação: $\vec{Y}=a+b x+c x^{2}$. Produção brachiāria,1981

7. Estimativas dos parāmetros da equação: $\bar{Y}=a+b x+c \sqrt{x}$. Produção arroz, 1981.

8 Estimativas dos parāmetros da equação: $\overline{\mathrm{Y}}=\mathrm{a}+\mathrm{bx}+\mathrm{c} \sqrt{\mathrm{x}}$. Produção brachiária,

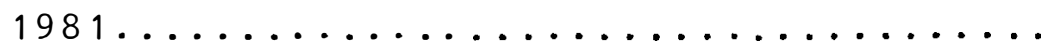


9 Produção esperada, produto médio, marginal e coeficiente de elasticidade para o arroz,

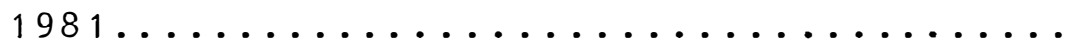

10 Produção esperada, produto médio, marginal e coeficiente de elasticidade para a brachiária, $1981 \ldots \ldots \ldots \ldots \ldots \ldots \ldots \ldots \ldots \ldots \ldots \ldots \ldots \ldots \ldots \ldots$

11 Valores da produção, receita, custo do adú bo e retorno por hectare, com os preços constantes. Experimento A, primeira época de plantio da brachiária. Ilha solteira,

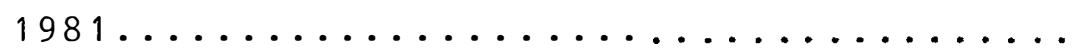

12 Valores da produção, receita, custo do adu bo e retorno por hectare, com os preços constantes. Experimento $B$, segunda época de plantio da brachiária. Ilha Solteira,

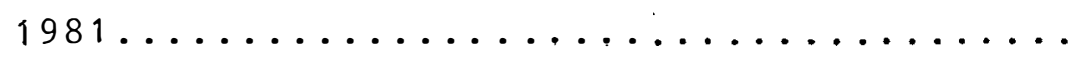

13 Valores da produção, receita, custo do adu bo e retorno por hectare, com os preços constantes. Experimento B, terceira época de plantio da brachiária. Ilha Solteira,

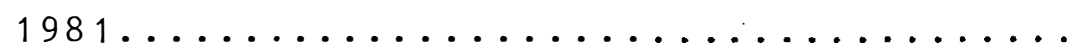

14 Valores da produção, receita, custo do adu bo e retorno por hectare, com os preços constantes. Experimento B. Ilha Solteira.. 
16 Quantidades ótimas de $\mathrm{P}_{2} \mathrm{O}_{5}$ (kg/ha) para vä rias alternativas de preços do arroz, brachiária e $\mathrm{P}_{2} \mathrm{O}_{3}$. Experimento A, primeira época de plantio da brachiária. Ilha Soltei

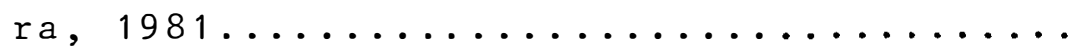

17 Quantidades ótimas de $\mathrm{P}_{2} \mathrm{O}_{5}$ (kg/ha) para váa rias alternativas de preços do arroz, brachiária e $\mathrm{P}_{2} \mathrm{O}_{5}$. Experimento $\mathrm{B}$, segunda épo ca de plantio da brachiária. Ilha Soltei-

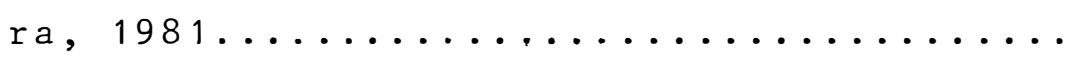

Quantidades ötimas de $\mathrm{P}_{2} \mathrm{O}_{5}$ (kg/ha) para vạ rias alternativas de preços do arroz, brachiária e $\mathrm{P}_{2} \mathrm{O}_{5}$. Experimento B, terceira época de plantio da brachiária. Ilha Soltei

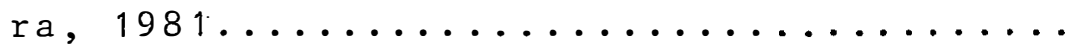

19 Quantidades ótimas de $\mathrm{P}_{2} \mathrm{O}_{5}$ (kg/ha) para vạ rias alternativas de preços do arroz, brachiária e $\mathrm{P}_{2} \mathrm{O}_{5}$. Experimento B. Ilha Soltei

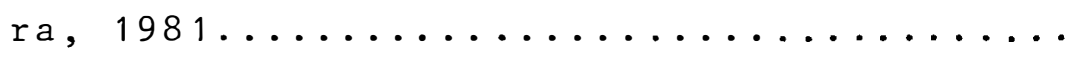


1 Curvas de demanda ef erta de $\mathrm{P}_{2} \mathrm{O}_{5}$ para

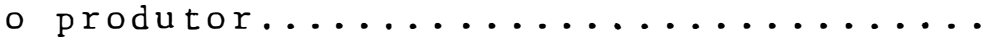


ANĀLISE ECONŌMICA DE DIFERENTES NİVEIS DE FŌSFORO NA PRODUÇÃO DE ARROZ CONSORCIADA COM BRACHIĀRIA EM SOLO SOB VEGETAÇÃO DE CERRADO

Maria Inez Espagnoli Geraldo Martins

Orientador: Josē Ferreira Noronha

\section{RESUMO}

Este estudo foi realizado com dados provenien tes de ensaio instalado no ano de.1981, na Fazenda Experimental da UNESP de Ilha Solteira, localizada no municipio de Selvíria, Mato Grosso do Sul, em região de cerrado. O delineamento adotado foi o de parcelas subdivididas com quatro repetições. Os tratamentos utilizados foram cinco ni.veis de fósforo $\left(0,75,150,225\right.$ e $300 \mathrm{~kg}$ de $\mathrm{P}_{2} \mathrm{O}_{5}$ por hectare) na forma de superfosfato simples. As parcelas são constituidas de niveis de fósforo e as subparcelas de época de plantio da brachiāria, que se realizou aos 10,20 e 30 dias após a emergência do arroz.

o objetivo principal deste trabalho foi determi nar as doses económicas de fósforo para a cultura de arroz quan do consorciada com brachiária e ainda estabelecer a melhor épo ca de se realizar esta consorciação. 
Foram utilizados dois modelos de função de produção: o quadrático e o raiz quadrada.

$$
\text { As principais conclusões deste trabalho são: }
$$

(a) A quantidade de $\mathrm{P}_{2} \mathrm{O}$ s a ser recomendada variou de 4 a $24 \mathrm{~kg}$ de $\mathrm{P}_{2} \mathrm{O}_{5}$ por hectare, para preços iguais aos correntes na é poca de instalação dos ensaios (novembro de 1981), deven do-se ressaltar que este é um valor relativamente baixo dạ das as caracteristicas dos solos de regiões de cerrado serem pobres em fósforo.

(b) As produções do arroz e da pastagem foram bem superiores nos experimentos instalados em 07 e 27 de outubro, o que sugere que o plantio do arroz deva ser.realizado neste periodo.

(c) Com base nas produções físicas obtidas, conclui-se que a pastagem deva ser semeada nas entrelinhas do arroz, de 10 a 20 dias após sua emergência, entretanto, quando se consi dera o valor total da produção (quantidade $x$ preço), perce be-se que a melhor época de plantio deve ser de 20 a 30 dias.

(d) Quando utilizou-se a função de resposta que inclui fósforo, blocos e o efeito de época de plantio da brachiária, so mente um experimento (o instalado em 07 de outubro) permitiu estabelecer a melhor época de planțio de brachiária, e esta época foi 13 dias após a emergēncia do arroz. 


\author{
ECONOMIC ANALYSIS OF DIFFERENT \\ PHOSPHORUS LEVELS IN RICE ASSOCIATED \\ WITH BRACHIARIA IN CERRADO REGION
}

Author: Maria Inez Espagnoli Geraldo Martins

Adviser: José Ferreira Noronha

\title{
SUMMARY
}

The present study was carried out in a Cerrado soil, within the Experimental Station of UNESP-Ilha Solteira, Selvíria, Mato Grosso do Sul.

The main purpose of this paper was to determine the economic rates of phosphorus for rice crop, associated with Brachiaria and to determine the best period to establish the association. The experimental design was a split-plot with four replications, and five P levels $(0,75,150,225$ and 300 $\mathrm{kg} \mathrm{P}_{2} \mathrm{O}_{5} / \mathrm{ha}$ as simple superphosphate). The main plot varied the P treatments and sub-plots, the time of establishment of the association ( 10,20 and 30 days after rice emergence). Quadratic and square root response functions were used.

The main conclusions of this work were: 
(a) Economic amounts of 4 to $24 \mathrm{~kg} \mathrm{P}_{2} \mathrm{O}_{5} / \mathrm{ha}$ should be recommended to the experiment, although these values are relatively low for the normally poor cerrado soils.

(b) The rice and pasture yields were superior in the experiments sown on october 7 and october 27.

(c) Based on yield data, it could be recommended Brachiaria at sowing at 10 and 20 days after rice emergence. However, for total yield value (production $x$ price), this date can be delayed to 20-30 days.

(d) By using a complete function, including phosphorus, block and sowing time of Brachiaria effects, only one experiment (that sowing on october, 07) permited to stablished the best time of sowing of Brachiaria, and this time was 13 days of the rice emergence. 


\section{INTRODUCAO}

Vảrias funçóes têm sido atribuidas à agricultura brasileira, entre elas, suprir a demanda crescentede alimentos no mercado interno e ainda, gerar excedentes exportáveis que sejam capazes de aliviar a balanca de pagamentos e aumentar a capacidade de imporiação do País.

A necessidade de aumentar a produção agrícola fez com que regiões até então pouco exploradas, como os cerra dos, fossem alvos de incentivos governamentais aumentando de maneira significativa o interesse pelo potencial agrícola des sas regiões.

No Brasil, os cerrados ocupam cerca de 200 milhões de hectares, sendo que aproximadamente $70 \%$ dessa área localiza-se nos Estados de Goiás, Minas Gerais e Mato Grosso.

Apesar de seu enorme potencial agricola, os cer rados tēm sido pouco explorados. Os principais obstáculos à produção agrícola residem na baixa fertilidade dos solos e na 
insuficiēncia hídrica resultante da irregular distribuicão pluviométrica. Mais recentemente, a principal restrição è a queda do nivel de atividade economica em geral e os elevados custos dos recursos para investimento e custeio.

Em contrapartida, são considerados aspectos positivos dessas áreas: suas boas condiçóes físicas para agricultura, topografia que facilita a mecanização, proximidadede grandes centros urónos, boa infra-estrutura de transportes e cंomunicações.

Algumas culturas tēm mostrado boa aptidão para os cerrados e entre elas o arroz que desempenha papel de destaque como cultura desbravadora. E cultivado sob.o sistema de sequeiro, soírendo oscilações na produtividade, em virtude das variações climáticas. Mesmo assim, sua utilização é bastante difundida em äreas novas, como redutora do custo de formaça de pastagens.

A própria dināmica da pesquisa vem demonstrando que a agrostologia tropical ainda está a exigir um gigantesco esforço do setor ciéntifico e tecnológico para se lograr uma maior produtividade dos bovinos. E é reservada ao Brasil uma significativa responsabilidade no estudo das pastagens tropicais, seja pelo tamanho do rebanho, pela disponibilidade de á reas, ou pelo papel da bovinocultura no desenvolvimento sócio-economico e na ocupação de novas áreas.

A área com pastagem no Brasil ocupa aproximadamente 165 milhões de hectares, sendo que $56,2 \%$ encontra-se em 
Minas Gerais, Goiās e Mato Grosso, dos quais $79,2 \%$ são pastagens naturais e $20,8 \%$ são cultivadas. Dados estes referentes ao ano de 1975 .

A capacidade de suporte média das pastagens naturais, nos periodos das águas e da seca, é estimada em cerca de 0,8 e 0,3 bovinos por hectare, respectivamente. Em pastagens cultivadas, a lotação média é ampliada para 2 e 0,8 bovi nos por hectare para os periodos referidos (EMBRAPA, 1979).

A elevação da capacidade de suporte das pastạ gens somente será possivel se os produtores aplicarem tecnolo gia apropriada, o que implica geralmente em maiores investimentos.

As pastagens são consideradas como a fonte mais ba rata para alimentar os ruminantes. O melhoramento das pasta gens através da melhoria da fertilidade do solo e da nutrição das forrageiras, visa principalmente sua maior produtividade e, conseqüentemente, um maior lucro.

É necessário corrigir a acidez e o baixo teor de matéria orgānica que resultam numa baixa disponibilidade de fósforo às plantas. Portanto, a adubação fosfatada e a cala gem são práticas imprescindiveis às regiões de cerrado, para obtenção e sustentação de bons rendimentos.

Apesar das pastagens cultivadas aumentarem a capacidade de suporte, ainda representam uma atividade não muito comum aos agricultores de regiões de cerrado, pelo seu alto custo de implantação, devido à necessidade do uso de corretivos e fertilizantes. Uma prätica que pode ser melhor estudada 
para minimizar o alto custo inicial, é a cunsorciação da pastagem com arroz.

o desconhecimento, por parte do produtor, da economicidade dessas alternativas, faz com que tecnologias mais aprimorads não sejam aplicadas. Neste contexto, um estudo eco nômico de fertilização se torna de grande importāncia por tes tar as respostas de culturas a diferentes niveis de nutriente, como também, por possibilitar a indicação da dose do fertilizante que seja ótima, de maneira a trazer retorno maior ao produtor agricola.

\section{1. Objetivos}

a) Estimar funções de produção para o arroz para a pasta gem , em função das doses de fósforo.

b) Estimar a dose ótima económica do fósforo para a cultura do arroz em consorciação com a pastagem.

c) Determinar as melhores épocas de plantio do arroz emcon sorciação com a pastagem.

\subsection{Orgainização do trabalho}

Após a revisão de literatura a ser apresentada na parte 2 , onde se deu enfoque principalmente para trabalhos que comparassem modelos de funções de produção, na parte 3 se rá descrito o materiale a metodologia a ser utilizada nestees tudo. Na parte 4, apresentaremos primeiramente os resultados obtidos nos experimentos, para em seguida serem discutidos os resultados estatisticos e económicos deste trabalho. 
Nas partes 5 e 6, respectivamente, serão apresentadas as conclusões e a literatura citada. 


\section{REVISÁO DE LITERATURA}

SILVA (1957) usou modelos quadrático, raíz quadrada e Cobb-Douglas para fazer uma anälise económica de expe rimentos de adubação com feijão, em quatro municípios localizados rá Zona da Mata do Estado de Minas Gerais. Para o município de Viçosa, o ajustamento das trēs funções matemáticas foi satisfatório, mas os resultados econômicos apresentados pela função quadrática foram mais coerentes com a teoria agronō mica .

LANZER (1970), realizou análise económica de um grupo de experimentos de fertilização e correção de solos argilosos na cultura do trigo, no Planalto Médio e Alto Uruguai, no Rio Grande do Sul. Os ensaios foram analisados em grupos, sendo utilizados os modelos Cobb-Douglas, quadrático, raíz quadrada e poténcia 3/2. A equação selecionada ao final foi u ma polinomial do tipo quadrática. O autor realizou análise com parativaentre máxima eficiēncia económica e máxima eficiēncia 
técnica, notándo que em MET se alcançariam produções físicas bem mais elevadas, mas que o resultado económico seria negativo.

VIEIRA (1970) fez uma comparação de quatro fun ções de produção aplicadas a ensaios fatoriais $3^{3}$ de adubação NPK em milho. Os modelos utilizados foram o raíz quadrada, potēncia $3 / 2$ e o de Mitscherlich, e foram comparadas com os resultados obtidos para o modelo quadrático por Campos (1967).

As principais conclusões obtidas foram:

a) Dos três modelos de regressão polinomial ajustados, dois revelaram-se praticamence iguais nos resultados: oquadrático e o poténcia 3/2. 0 uso do modelo quadrático foi indicado por apresentar maior simplicidade de cálculos que o de grau 3/2. b) A equiação de Mitscherlich é recomendada para a determinação da dose economica do nutriente porque leva a soluções sa tisfatórias através de métodos matemáticos simples. Pcrém, se houver queda na produção com doses altas do nutriente a re gressão polinomial é mais recomendadá, preferencialmente o modelo raiz quadrada .

TEIXEIRA et alii (1971) efetuaram anälise agro económica de trés experimentos de milho instalados em Sete La goas 65/66, Capinópolis 66/67 e 67/68 no Estado de Minas Gerais, relacịonando produções de milho com popụlação de plantas e niveis de nitrogēnio. o modelo estatistico escolhido foi a função quadrática, sendo que os coeficientes de determinação múltipla encontrados nos trés ensaios foram elevados. 0 
maior foi obtido para o ensaio de Capinópolis, 1966/67 ( $\mathrm{R}^{2}=$ $=0,9815)$, indicando que $98,15 \%$ da variação total na produção de milho, por hectare, é explicada através da regressão quadrática considerada. Em todos os ensaios o efeito do $N$ foi maior que o de densidade de plantas sobre a produção do milho. Para os ensaios de Capinópolis os niveis ótimos de aplicação do $N$ e população das plantas estavam além dos limites usados no experimento.

VIEIRA et alii (1971), analisando um grupo de 50 ensaios fatoriais $3^{3}$ de adubação NPK em milho, conduzidos em terra roxa legitima, na região de Ribeirão Preto nos anos agrí colas $1957 / 58,1958 / 59,1959 / 60$ e 1960/61, concluiram que quan do existe queda na produção devida à adubação excessiva, as re gressões quadrática e raiz quadrada expressam melhor o fenōmeno biológico. Entretanto, a função de Mitscherlich é aconse lhável se não houver queda na produção, pois os processos bio lógicos envolvidos na adubação são perfeitamente identificados com os parāmetros dessa função.

NOVAIS \& DEFELIPO (1971), para obter informações sobre os níveis ótimos de NPK a serem utilizados na cultura de arroz, em regiões de cerrado, instalaram um ensaio de adubação em Patos de Minas. Utilizou-se um delineamento em fa torial $3 \times 3 \times 3$ com NPK em 3 níveis com uma só repetição. Foi feita a anālise de variāncia dos dados e ajustada uma equaço quadrática, tomando-se a produção como variável dependente de fósforo e potássio, sendo eliminado o nitrogēnio por ter apre 
sentado resposta negativa e por não contribuir para melhor ajustamento da equação. Os autores verificaram uma resposta a tamente significativa à aplicação do fósforo, um aumento da produção em resposta à aplicação de potássio, embora não significante e, uma diminuição na produção com a aplicação de N. LESSINGER (1972), analisou o efeito residual do fósforo e calcário em pastagem e trigo de Vacaria, RS, bem có mo a diferença de produção havida pelo uso ou não da prática de adubação de manutenção. Para isto, testou vinte e dois sub modelos estatisticos, sendo vinte do modelo quadrático e dois do modelo $3 / 2$, para conseguir uma equação de regressão que per mitisse a maximização - económica em relação ao calcá rio e fósforo. Pelo fato do coeficiente do termo quadráticopara ofósforo ( $\left.\mathrm{P}^{2}\right)$ ter apresentado valores positivos, e pela falta de significāncia da variável $\mathrm{P}^{3 / 2}$, não foi possível maxi mizar económicamente $\quad \cdot \quad$ o uso do fósforo. Isto só foi possivel em relação ao calcário. Os resultados mostraram ser vantajosa a adubação de manutenção, pois determinou um acréscimo da produção da pastagem e do trigo.

StEFANELO (1975) usou os modelos Cobb - Douglas, potēncia 3/2, quadrático e raiz quadrada para analisar economicamente um grupo de dez experimentos com fósforo, potássio e calcário aplicados em soja, no Rio Grande do Sul. Em todos os locais estudados, o modelo Cobb-Douglas apresentou o coefi ciente de determinação múltipla, $R^{2}$, sensivelmente mais baixo que os outros trés modelós. Somente para um local, o modelo 
raiz quadrada se ajustou melhor aos dados experimentais. Nos outros locais, a superficie de resposta foi fornecida através do modelo quadrático. O autor, conclui afirmando que entre os modelos estudados, o quadrático com interação entre os fatores é o que melhor define a superficie de resposta em relação à fertilização e calagem.

Costa (1977) usou modelos quadrätico, raiz qua drada e potēncia $3 / 2$, em 27 ensaios de adubação NPK, na prodú ção de arroz em vários anos agricolas, no Estado de Goiás. Trabalhou com os dados dos ensaios individualmente e foram feitos cinco grupos de experimentos por ano agricola e um envolvendo dois anos agricolas. Os modelos quadrático e potencia $3 / 2$ tiveram comportamento idēnticos, razão pela qual o último não foi considerado. A recomendação de adubação foi dificultada pelo fato de os intervalos de confiança das doses económicas terem sido amplos. O autor recomenda a determinação das doses económicas para grupos de ensaios, por haver maior homogeneidade nos tratamentos.

MENEGUELLI e TOLLINI (1978) dizem que o problema principal na escolha da forma algébrica, a ser ajustada a resultados e ensaios de adubação, estä no desconhecimento da forma exata no mundo real. Realizaram um ensaio simulado tentando obter alguma idéia sobre as conseqüências de se usar de terminada forma quando a verdadeira no mundo simulado, é dife rente.

Para isto, consideraram quatro formas básicas: 
quadrática, raiz quadrada, Mitscherlich e linear. Concluem di zendo que a função raiz quadrada, em geral, mostrou desempenho melhor do que as outras funções, e que a vantagem cłara da função raiz quadrada, demonstrada na situação simulada do estudo, é acentuada pelo custo muito menor do ajustamento das funções lineares nos parämetros, relativamente à não linear.

LIMA (1979) utilizou dados de dois experimentos de adubação NPK em milho, com diferentes populações de plantas, conduzidos em dois solos (cerrado e terra roxa), do Triān gulo Mineiro. Na análise económica dos dados, o modelo que me lhor se ajustou foi o quadrático quando comparado ao logaritmico e ao da raiz quadrada. No cerrado, as produções máximas, tạ to físicas como econōmicas foram obtidas a niveis de população de plantas praticamente iguais, sendo que as equações encontradas nãor permitiram a determinação das doses ótimas económi cas .

GOMINHO e MAFRA (1979), utilizaram dados de experimento instalado em São João, Pernambuco, no ano de 1978 , que relaciona a produção do sistema consorciado feijão $x$ milho com níveis de $\mathrm{P}_{2} \mathrm{O}_{5}$. A função quadrática foi escolhida por simplicidade de cálculos, e comparada com a raiz quadrada e a Mitscherlich. A função raiz quadrada teve bom ajustamento tan to para o feijão quanto para o milho, entretanto apresentou doses de adubação que tornam os rendimentos físicos máximos situados completamente fora dos limites estabelecidos no experi mento tendo mostrado ainda uma dose ótima muito baixa em rela 
ção a função quadrática, aos mesmos preços. Comparando-se os coeficientes de determinação de uma e de outra, observou-se que a função quadrática apresentou valores maiores, indicando que esta função teve um melhor ajustamento.

A dificuldade do uso da função Mitscherlich para dois produtos está no fato de que esta admite apenas uma função crescerte que tende para um valor assintótico: quando cresce a dose do nutriente. A necessidade de fertilizante varia de cultura para cultura, então é possivel que, no caso da consorciação haja mais facilmente queda de produção em pelo menos uma das culturas, com o emprego de doses mais elevadas de fertilizantes. Não calcularam todavia a dose ótima com a e quação Mitscherlich, dadas estas limitações.

PORTO (1980) para comparar trés funções de produção (a quadrática, a Mitscherlich e a raiz quadrada), utili zou dados de experimento com trigo conduzidos por 4 anos consecutivos em Passo Fundo/RS. Além do nitrogēnio, outros 4 fatores foram estudados: calagem, tipos de preparo de solo, res teva e densidade de semeadura.

Chegou às seguintes conclusões: (a) dos trés mo delos utilizados, o quadrático e o raiz quadrada apresentaram ajustamentos ber melhores; (b) a dose económica varia muito, dependendo das condições climáticas. Isto mostra o cuidado que se deve ter para se recomendar aplicação de um dado nutriente baseado em dados experimentais de apenas um ano. 
.13.

\section{MATERIAL E MÉTODOS}

\subsection{Haterial}

Os dados básicos utilizados neste estudo foram obtidos através de ensaios de adubação de arroz consorciado com pastagem, conduzidos pela autora e realizados no ano agricola 1981/1982, na Fazenda Experimental da UNESP, "Campus" de Ilha Solteira, situada no municipio de Selviria, Estado de Mato Gros so do sul.

o delineamento experimental utilizado foi o de parcelas subdivididas, com 5 tratamentos principais e 3 subtratamentos, distribuidos em blocos ao acaso com quatro repetições. Os tratamentos estão especificados na Tabela 1. 
Tabela 1 - Tratamentos utilizados no experimento.

Tratamentos principais

Subtratamentos (a) Niveis de $\mathrm{P}_{2} \mathrm{O}_{5}$ :

$0,75,150,225$ e $300 \mathrm{~kg}$ por hectare

(b) Época de plantio da brachiäria:

10,20 e 30 dias após a emergéncia do arroz

As dimensões das parcelas foram de $6 \times 3 \mathrm{~m}$ e todas elas receberam 2 t de calcário dolomitico, por hectare, a plicado a lanço trinta dias antes do plantio do arroz, e 200 kg/ha da fórmula 4:20:20 no sulco de plantio do arroz.

o arroz, variedade IAC-25, foi semeado em sulcos distanciados de $0,50 \mathrm{~m}$ e a brachiäria (B. decumbens Stapf.) foi semeada entre as linhas do arroz.

A fonte de $\mathrm{P}_{2} \mathrm{O}_{5}$ usada foi o superfosfato simples, que foi aplicado a lanço na parcela toda :

-Foram instalados três experimentos, onde o que se variou foi a época de plantio do arroz. o primeiro experimento, denominado A, foi plantado em 07/10/81, o segundo em $27 / 10 / 81$ e o terceiro (C) em 16/11/81. 
.15 .

\title{
3.2. Métodos
}

\subsubsection{Modelo estatistico}

\author{
(a) Equações estimadas \\ As equações matemáticas ajustadas aos dados ex \\ perimentais foram as dos tipos quadrático (1) e raiz quadra- \\ da (2), por terem sido, segundo a revisão de literatura as que \\ melhor se ajustaram a dados experimentais.

$$
\mathrm{Y}_{i}=\alpha+\beta \mathrm{x}_{i}+\gamma \mathrm{x}_{i}^{2}+\varepsilon_{i}
$$$$
\mathrm{Y}_{i}=\alpha+\beta \mathrm{x}_{i}+\gamma \sqrt{\mathrm{x}}_{i}+\varepsilon_{i}
$$

onde os $\mathrm{Y}_{i}$ representam a produção de arroz em kg por hectare 
ou produção de brachiária em kg de massa verde por hectare e $\mathrm{x}_{i}$ representa o número de doses do nutriente $\mathrm{P}_{2} \mathrm{O}_{5}$ por hectare. Os sinais dos coeficientes deverão ser $\gamma<0$ pa ra a função quadrática e $\gamma>0$ para a raiz quadrada, para que elas apresentem rendimentos marginais decrescentes.

As duas funções implicam em rendimentos margi nais decrescentes para o insumo, o que parece corresponder à situação real na resposta a fertilizantes. A função quadrática tem seus produtos marginais $\left(\frac{d}{d x}\right)$ Iineares, indicando que diminuem em uma quantidade constante quando se aumentam as quantidades dos insumos, enquanto que na função raiz quadrada os produtos marginais diminuem a uma taxa decrescente (VALDÉS, 1967).

Portanto, tanto a função quadrática comoa raiz quàdrada são aceitas do ponto de vista lógico, já que refletem bem as condições reais do efeito de fertilizantes.

Nestas equações, os $\varepsilon_{i}$ são erros aleatórios que pressupõe-se independentes, com média zero, distribuição normal e variância $\left(\sigma^{2}\right)$ constante. Tomando-se a, b e c como esti mativas dos mínimos quadrados dos parāmetros $\alpha$, $\beta$ e $\gamma$ respectivamente, e $\bar{y}$ sendo a produtividade estimada, então, as esti mativas dos moderos adotados ficam: 


$$
\hat{Y}=a+b x+c x^{2}
$$

e

$$
\bar{Y}=a+b x+c \sqrt{ } x
$$

(b) Testes das hipöteses

Para testar a significāncia dos coeficientes da regressão, utilizou-se o valor de "t", que é a razão entre o coeficiente de regressão e seu desvio padrão.

1. Função quadrática

Para que esta função apresente um ponto de máxí mo e este tenha abscissa positiva é necessārio que o termo linear seja positivo e o termo quadrático negativo.

Coeficiente do termo 1 inear:

$\mathrm{H}_{0}: \beta=0$

contra a alternativa:

${ }_{\mathrm{A}}: \beta>0$

Para o termo quadrático, a hipótese nula será testada contra a alternativa

$$
\mathrm{H}_{\mathrm{A}}: \gamma<0
$$




\section{Função raiz quadrada}

Para que esta função apresente um ponto de máximo é necessārio que o termo linear seja negativo e o termo com raiz quadrada positivo. Portanto, no caso do coeficiente do termo linear estaremos testanto a hipótese nula

$$
\mathrm{H}_{0}: \mathrm{B}=0
$$

contra a alternativa

$$
\mathrm{H}_{\mathrm{A}}: \mathrm{B}<0
$$

Para o termo em raiz quadrada, a hipótese nula será testada contra a alternativa:

$$
\mathrm{H}_{\mathrm{A}}: \gamma>0
$$

Segundo WONNACOTT e WONNACOTT (1976) a inter pretação dos resultados da regressão deve ser feita com a mäxima cautela. Se temos razões para supor que a nossa variável independente $(x)$, esteja relacionada positivamente com a variàvel ( $Y$ ) e o coeficiente " $t$ " para o termo x nãofor estatis ticamente significativo, isto não prova a não existência de relação entre $x$ e Y. Qualquer valor positivo de "t" tende a afirmar nossa suposição inicial. Contudo, à medida que "t" se torna menor, nossa evidēncia estatistica se torna mais fraca. Somente se "t" for zero ou negativo, os resultados estatisticos contradizem a expectativa anterior. 


\subsubsection{Modelo econōmico}

$$
\text { Pressupõe-se competição perfeita no mercado de }
$$

fatores e de produtos e admite-se que o processo de produção possa ser representado pela seguinte função de produção:

$$
Y=f\left(x ; c_{1}, \ldots, c_{n}\right)
$$

onde consideramos apenas variação no uso de fertilizante $x\left(\mathrm{P}_{2} \mathrm{O}_{5}\right)$, mantendo os demais constantes. A função de lucro no caso de dois produtos e apenas um fator variável pode ser definida por:

$$
\pi=P_{A} Y_{A}+P_{B} Y_{B}-P_{X} X-C
$$

onde: $\quad \pi=$ renda 1 iquida;

$$
\begin{aligned}
& \mathrm{Y}_{\mathrm{A}}=\text { quantidade produzida de arroz; } \\
& \mathrm{P}_{\mathrm{A}}=\text { preço unitário do arroz; } \\
& \mathrm{Y}_{\mathrm{B}}=\text { quantidade produzida da pastagem; } \\
& \mathrm{P}_{\mathrm{B}}=\text { preço unitário da pastagem; } \\
& x=\text { nümero de doses de fósforo }\left(\mathrm{P}_{2} \mathrm{O}_{5}\right) \text { por hectare; } \\
& \mathrm{P}_{\mathrm{x}}=\text { preço unitário do fósforo, incluindo os custos va } \\
& \text { riáveis de aplicação do mesmo; } \\
& C=\text { custos fixos. }
\end{aligned}
$$

o preço unitário de $\mathrm{P}_{2} \mathrm{O}_{5}$ foi determinado partindo-se do preço unitário do superfosfato simples, posto na fazenda, levando-se em conta que o mesmo contém cerca de $18 \%$ de $\mathrm{P}_{2} \mathrm{O}_{5}$. Ao preço unitário do $\mathrm{P}_{2} \mathrm{O}_{5}$, foram incluídos os custos 
variāveis de aplicaça do mesmo no solo, como mostra a Tabe 1 a 2 .

Tabela 2 - Estimativa do custo de aplicação de fósforo por hectare, ano de 1981.

Itens

Quantidade

$75 \mathrm{~kg}$

$1,14 \mathrm{~h}$

$1,69 \ell$

óleo diese1

Lubrif icantes

Despesa total com insumo

Custo unitärio ( $\mathrm{Cr} \$ / \mathrm{kg}$ de $\mathrm{P}_{2} \mathrm{O}_{5}$ )
Preço unitário

$(\mathrm{Cr} \$)$
Cus to do insumo aplicado

$\begin{array}{lrrr}\mathrm{P}_{2} \mathrm{O}_{5} & 75 \mathrm{~kg} & 113,00 & 8.475,00 \\ \text { Mão-de-obra } & 1,14 \mathrm{~h} & 112,37 & 128,10 \\ \text { Óleo diesel } & 1,69 \ell & 50,00 . & 84,50\end{array}$

$-$

FONTE: Dados da pesquisa.

A estimativa do custo de aplicação de $\mathrm{P}_{2} \mathrm{O}_{5}$ por hectare, foi calculado para novembro de 1981, época de ins talação do experimento, por maior facilidade na obtenção dos dados. Por outro lado, o preço do quilograma de arroz pago ao produtor, na mesma ocasião, foi obtido considerando-se os prẹ ços publicados na revista "Informações Econōmicas", do Instituto de Economia Agricola (IEA) para a DIRA de Araçatuba e que era de $\operatorname{Cr} \$ 28,75$. Deve-se ressaltar que este preço utilizado pá ra o arroz tende a superestimar a dose ótima, jà que se trata 
de um valor tomado na época de entressafra do produto, quando os preços estão mais elevados.

Para se calcular o preço da pastagem, usou-se a tabela de Exigencias Nutritivas para gado de corte em termos de Matéria Seca por animal e por dia, segundo a categoria e o peso. Esta tabela é baseada em recomendações da Comissão de Nutrição Animal do Conselho Nacional de Pesquisas dos Esta dos Unidos (JARDIM, 1976).

Foram feitas anālises de Matéria Seca da Pastä gem no Laboratório deNutrição Animal da UNESP de Ilha Soltei ra, e calculado com base na tabela fornecida por JARDIM, o consumo de pastagem por animal e por dia. o valor do aluguel de pasto por cabeça por més, foi obtido de "Informações Econó micas" também para a DIRA de Araçatuba. o cálculo do preço do kg da pastagem encontra-se no Apēndice*1.

o produtor interessado em maximizar seu lucro, deverá maximizar a função expressa em (5). Para que esta função seja maximizada, duas condições devem ser satisfejtas. A primeira delas é que a derivada de $\pi$ em relação x seja zero. Então de (5) obtemos:

$$
\frac{d \pi}{d x}=P \frac{d \vec{Y}_{A}}{d x}+P_{B} \frac{d \vec{Y}_{B}}{d x}-P_{x}=0
$$

e a derivada segunda seja menor do que zero: 


$$
\frac{d^{2} \pi}{d x^{2}}=P_{A} \frac{d^{2} \hat{Y}_{A}}{d x^{2}}+P_{B} \frac{d^{2} \hat{Y}_{B}}{d x^{2}}<0
$$

Obtidas as estimativas das funções de resposta do arroz e da brachiária, usando-se as funções (3) oı (4), e de acordo $\operatorname{com}(6)$, podemos calcular as doses economicas $x *$ de fósforo.

$$
\text { Assim, para o modelo quadrático, no caso do a } \underline{r}
$$

roz:

$$
\overline{\mathrm{Y}}_{A}=a_{A}+b_{A} x+c_{A} x^{2}
$$

e da brachiària:

$$
\overline{\mathrm{Y}}_{B}=a_{B}+b_{B} x+c_{B} x^{2}
$$

temos:

$$
\frac{d \bar{Y}_{A}}{d x}=b_{A}+2 c_{A} x
$$

e

$$
\frac{d \hat{Y}_{B}}{d x}=b_{B}+2 c_{B} x
$$

A condição necessāria para renda líquida máxima fica:

$$
\frac{d \pi}{d x}=P_{A}\left(b_{A}+2 c_{A} x\right)+P_{B}\left(b_{B}+2 c_{B} x\right)-P_{x}=0
$$


segue-se que:

$$
x *=\frac{P_{x}-P_{A} b_{A}-P_{B} b_{B}}{2\left(c_{A} P_{A}+{ }_{B} P_{B}\right)}
$$

Se for usado o modelo raiz quadrada,

$$
\widehat{Y}_{A}=a_{A}+b_{A} x+c_{A} \sqrt{ } x
$$

e

$$
\widehat{\mathrm{Y}}_{\mathrm{B}}=\mathrm{a}_{\mathrm{B}}+\mathrm{b}_{\mathrm{B}} \mathrm{x}+\mathrm{c}_{\mathrm{B}} \sqrt{ } \mathrm{x}
$$

temos:

$$
\frac{d \overline{\mathrm{Y}}_{A}}{d x}=b_{A}+\frac{c_{A}}{2 r^{\prime} x}
$$

e

$$
\frac{d \hat{Y}_{B}}{d x}=b_{B}+\frac{c_{B}}{2 \sqrt{ } x}
$$

A condição necessäria para a renda liquida má-

xima fica:

$$
\frac{d \pi}{d x}=P_{A}\left(b_{A}+\frac{c_{A}}{2 \sqrt{x}}\right)+P_{B}\left(b_{B}+\frac{c_{B}}{2 \sqrt{x}}\right)-P_{x}=0
$$

segue-se que:

$$
x *=\frac{\left(P_{A} c_{A}+P_{B} c_{B}\right)^{2}}{4\left(P_{X}-P_{A} b_{A}-P_{B} b_{B}\right)^{2}}
$$




\subsubsection{Modelo da função de resposta}

Com a finalidade de estudar a influēncia do fós foro, da época de plantio da brachiária e o efeito de blocos utilizaremos o seguinte modelo:

$$
Y_{i}=\alpha_{1}+\delta_{1} B_{1}+\delta_{2} B_{2}+\delta_{3} B_{3}+\delta_{4} P+\delta_{5} E+\delta_{6} P^{2}+\delta_{7} E^{2}+\delta_{8} E P+u_{i}
$$

onde:

$$
\begin{aligned}
\mathrm{Y}_{i}= & \text { produção de arroz em } \mathrm{kg} / \mathrm{ha} \text { ou produção de brachiária em } \\
& \mathrm{kg} \text { de massa verde/ha; } \\
\mathrm{B}_{i}= & \text { blocos; } \\
\mathrm{P}= & \text { fósforo; } \\
\mathrm{E}= & \text { época de plantio da brachiāria: } 10,20 \text { e } 30 \text { dias a- } \\
& \text { pós a emergēncia do arroz; } \\
\mathrm{u}_{i}= & \text { erro aleatório. }
\end{aligned}
$$




\title{
4. RESULTADOS E DISCUSSÃO
}

\author{
Neste capitulo dividiremos a apresentação dos \\ resultados e sua discussão em trés partes: resultados descri- \\ tivos, estatisticos e econömicos.
}

\subsection{Resultados descritivos}

Os rendimentos obtidos nos cinco tratamentos nos diferentes experimentos são apresentados na Tabela 3 (arroz) e na Tabela 4 (pastagem). As denotações "a", "b" e "c", são a lusivas às épocas de plantio da brachiária, ou seja, 10, 20 e 30 dias respectivamente, após a emergēncia do arroz. Devemos ter em mente entretanto, que a importāncia relativa da brachiária está subestimada pois a produção foi obtida considerando-se apenas um corte, o que não reflete a realidade, já que a produção da pastagem se estende por todo o ano e por vá 
Tabela 3 - Rendimentos obtidos na cultura de arroz ( $\left.\mathrm{Y}_{A}\right)$, por tratamento, nos diferentes experimentos (média de quatro repetições), em $\mathrm{kg} / \mathrm{ha}, 1981$.

\begin{tabular}{|c|c|c|c|c|c|c|}
\hline \multirow{2}{*}{$\begin{array}{l}\text { Experi- } \\
\text { mentos }\end{array}$} & \multicolumn{5}{|c|}{ Niveis de fósforo ( $\mathrm{kg}$ de $\mathrm{P}_{2} \mathrm{O}_{5} / \mathrm{ha}$ ) } & \multirow{2}{*}{ Médias } \\
\hline & 0 & 75 & 150 & 225 & 300 & \\
\hline \multicolumn{7}{|l|}{$A(07 / 10)$} \\
\hline$a^{2}$ & 736 & 749 & 1437 & 921 & 1142 & 997 \\
\hline $\mathrm{b}$ & 1835 & 1856 & 1964 & 851 & 2491 & 1799 \\
\hline c & 1406 & 2310 & 1704 & 1881 & 2603 & 1980 \\
\hline \multicolumn{7}{|l|}{$B(27 / 10)$} \\
\hline $\mathrm{a}$ & 1836 & 1837 & 1678 & 1591 & 1806 & 1750 \\
\hline $\mathrm{b}$ & 1934 & 1968 & 1894 & 1501 & 1750 & 1809 \\
\hline c & 1561 & 1989 & 2001 & 1710 & 2107 & 1874 \\
\hline \multicolumn{7}{|l|}{$C(16 / 11)$} \\
\hline . a & 240 & 106 & 51 & 71 & .66 & 107 \\
\hline $\mathrm{b}$ & 332 & 204 & 211 & 161 & 241 & 230 \\
\hline c & 393 & 313 & 392 & 317 & 362 & 355 \\
\hline
\end{tabular}


Tabela 4 - Rendimentos obtidos com a pastagein $\left(\mathrm{Y}_{B}\right)$, por tratamento, nos diversos experimentos (média de quatro repetições), em kg/ha, 1981.

\begin{tabular}{|c|c|c|c|c|c|c|}
\hline \multirow{2}{*}{$\begin{array}{l}\text { Experi- } \\
\text { mentos }\end{array}$} & \multicolumn{5}{|c|}{ Niveis de fösforo ( $\mathrm{kg}$ de $\mathrm{P}_{2} \mathrm{O}_{5} / \mathrm{ha}$ ) } & \multirow{2}{*}{ Médias } \\
\hline & 0 & 75 & 150 & 225 & 300 & \\
\hline \multicolumn{7}{|l|}{$A(07 / 10)$} \\
\hline$a^{1}$ & 10458 & 11041 & 10375 & 10541 & 9999 & 10483 \\
\hline $\mathrm{b}$ & 5041 & 12291 & 8291 & 13750 & 11250 & 10125 \\
\hline c & 4333 & 3208 & 2500 & 2503 & 2765 & 3062 \\
\hline \multicolumn{7}{|l|}{$B(27 / 10)$} \\
\hline a & 3708 & 7958 & 9750 & 9166 & 9166 & 7950 \\
\hline $\mathrm{b}$ & 2791 & 6791 & 8958 & 9541 & 10625 & 7741 \\
\hline c & 2208 & 5458 & 3166 & 6250 & 5500 & 4516 \\
\hline \multicolumn{7}{|l|}{$C(16 / 11)$} \\
\hline $\mathrm{a}$ & 6291 & 6541 & 8833 & 7125 & 7875 & 7333 \\
\hline $\mathrm{b}$ & 6333 & 7416 & 8250 & 6458 & 8499 & 7391 \\
\hline c & 2208 & 2827 & 3166 & 4000 & 1625 & 2765 \\
\hline
\end{tabular}

rios anos dependendo do manejo.

Se analisarmos a Tabela 3 podemos notar que a produção média de arroz obtida foi bem superior nos experimentos $A(07 / 10)$ e $B(27 / 10)$, quando comparada com o experimento C $(16 / 11 / 81)$.

Quando se observa as produções de arroz dentro de cada período de consorciação, verificamos que os picos de 
produção ocorreram principalmente nas épocas b e c, que se re ferem ao plantio da brachiāria realizado 20 e 30 dias após a emergēncia do arroz, respectivamente.

A Tabela 4 nos mostra que os picos de produção da pastagem ocorreram também nos dois primeiros experimentos ( $A$ e B), na época b de plantio da brachiária, embora a produção média maior tenha ocorrido, nos experimentos A e B, na època a de consorciação.

Quando calculamos o valor total da produção, $\underline{u}$ tilizando os preços do arroz ( $\operatorname{Cr} \$ 28,75)$ e da brachiäria (Cr\$... $0,56)$ multiplicados pelas respectivas quantidades médias produzidas $\left(\dot{\bar{Y}}_{A}\right.$ e $\left.\overline{\mathrm{Y}}_{B}\right)$, notamos que o valor total da produção é maior quando a pastagem é instalada 20 a 30 dias após a emer gència dos arroz.

Quando comparamos as duas tabelas, sem levar. em consideração os niveis de fósforo, podemos verificar que nos très experimentos, à medida que a produção média do arroz aumenta, a produção média de brachiária diminui, o que de ve ser devido à competição entre as duas culturas. KORNELIUS et alii (1982), constataram que quando o plantio de $B$. decumbens se deu entre as linhas de arroz, houve uma grande redução na produção do arroz, devido a um maior desenvolvimento e competição da forrageira com o arroz. 


\subsection{Resultados estatisticos}

Pela análise de variância (Tabelas 20 a 25 do Apēndice 2), verifica-se que houve significāncia estatística para época de consorciação, tanto para a brachiária como para o arroz, exceção feita apenas para o arroz no experimento B (27/10/81). Houve diferença significativa para fósforo apenas no experimento $A(07 / 10 / 81)$, para o arroz. O que se pode concluir da análise destas tabelas é que tanto para o arroz como para a brachiária, a variável que teve um efeito mais signifi cativo foi a época de consorciação e não o fósforo como era de se esperar.

Após a análise de variāncia, foram estimadas as funções de resposta. Para que se pudesse escolher as equações que melhor se ajustassem ao processo produtivo analisado, ten tou-se utilizar os seguintes indicadores de escolha, que são os mesmos usados por SILVA (1967).

(1) o sinal dos coeficientes parciais da regressão deveria ser coerente com a teoria econōmica;

(2) o valor do coeficiente de determinação ( $\left.r^{2}\right)$ fosse o maior possivel;

(3) os coeficientes parciais da regressão fossem significativamente diferentes de zero, a um nivel de probabilidade de no minimo $10 \%$. 
Pela análise dos resultados obtidos, pudemos notar que as funções referentes à produção de arroz, tanto a quadrätica (Tabela 26 ) como a raiz quadrada (Tabela 27) apresentaram na maioria das equaços, os sinais dos coeficientes par ciais da regressão conträrios ao esperado. Somente duas funções apresentaram os sinais dos coeficientes coerentes com o esperado para os dois tipos de função estimada, e outras duas para a função raiz quadrada.

Esta inversão de sinal dos coeficientes parciais da regressão ocorrida com o arroz, não aconteceu da mes ma forma com a brachiária, onde apenas uma função de resposta apresentou sinal contrário ao esperado nos dois tipos de função estimadas. As Tabelas $26,27,28$ e 29 do Apēndice 2, trazem as estimativas dos parāmetros, os desvios padrões, valores de "t" $e^{*} r^{2}$ para todas as funções de resposta estimadàs. $0 r^{2}$, coeficiente de determinação, definido como a razão entre a soma do quadrado da regressão e a soma do quadrado total, indica a proporção da variação na produção que é explicą da pela regressão.

As estimativas dos parāmetros, os valores de $r^{2}$, de "t" e os desvios padrões do modelo (1) são apresentados nas Tabelas 5 e 6 , e do modelo (2), nas Tabelas 7 e 8 . Es tas tabelas foram montadas com base nas funções estimadas para o arroz, onde todas as funções que apresentaram os sinais dos coeficientes coerentes com o esperado, foram consideradas. Devemos ressaltar que a denotação "p", refere-se à produção 
do arroz (Tabela 7) e de pastagem (Tabela 8), em função dos niveis de fósforo, sem levar em consideração a época de plantio da brachiária. No caso deste trabalho em que outros fatores estão influindo nos resultados, como por exemplo a época de consorciação, os coeficientes de determinação usados nas Tabelas 5 a 8 foram calculados como a razão entre a soma do quadrado da regressão e a soma do quadrado do efeito de fósfo ro para cada caso especifico.

Pelo que podemos verificar nestas tabelas, os coeficientes parciais da regressão foram não significativos, exceção feita apenas ao coeficiente do termo raiz quadrada para o caso B-p (Tabela 8). Apesar destes coeficientes não terem a presentado significāncia estatistica, se considerarmos nossa pressuposição inicial a respeito do sinal destes coeficientes, ou seja se temos razões para crer que a variável x esteja relacionada positivamente com ( $Y$ ), mesmo que o coeficiente "t" para o termo $x$ não for estatisticamente significativo, qualquer valor positivo de $t$, pode ser considerado significativo. Segundo CRUZ (1975), "em agricultura onde há uma grande componente de risco e incerteza devido a variações climáticas, pra gas e doenças, não se deve ser excessivamente rigoroso no que diz respeito aos niveis de significância estatisticos". 


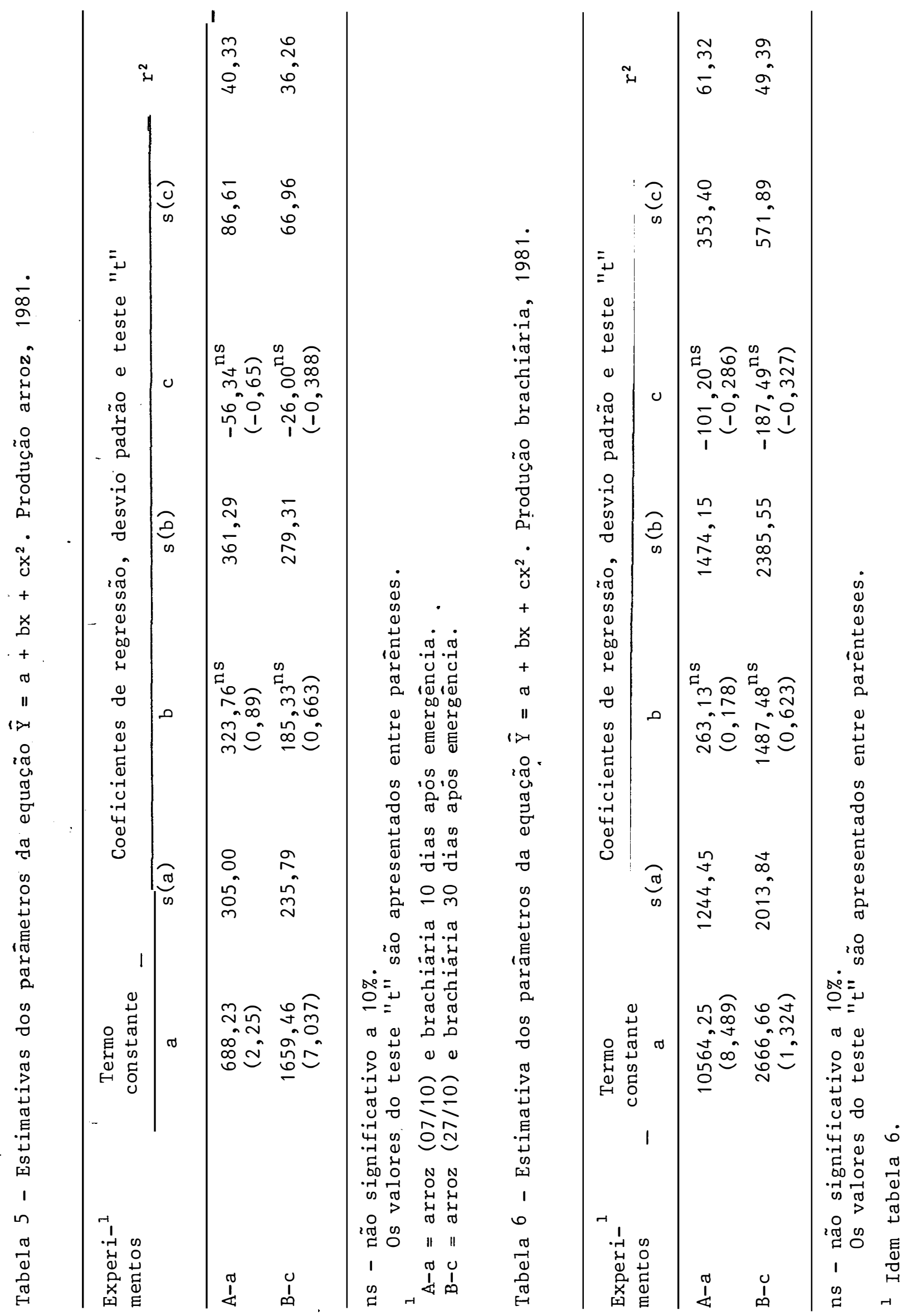




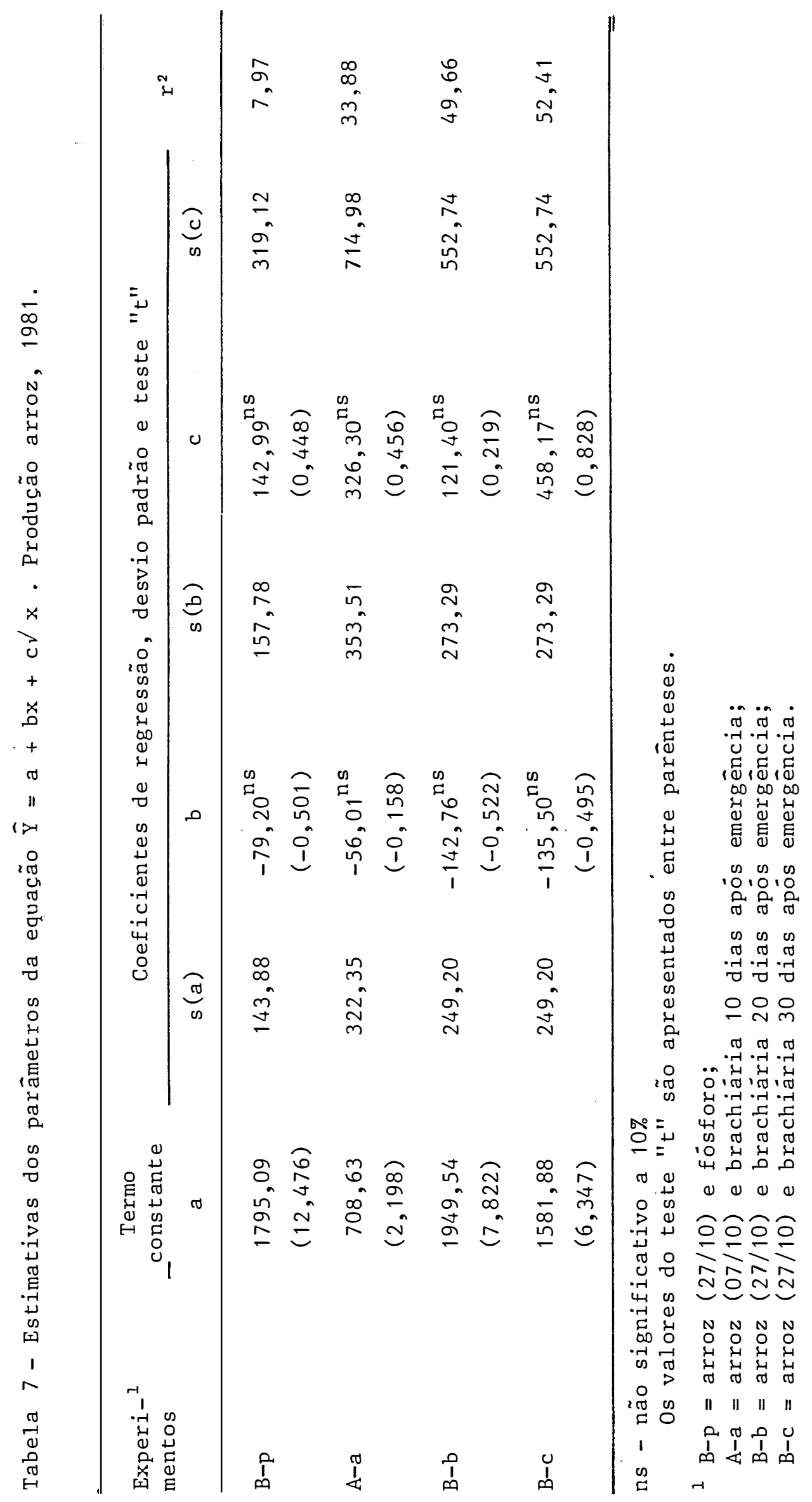




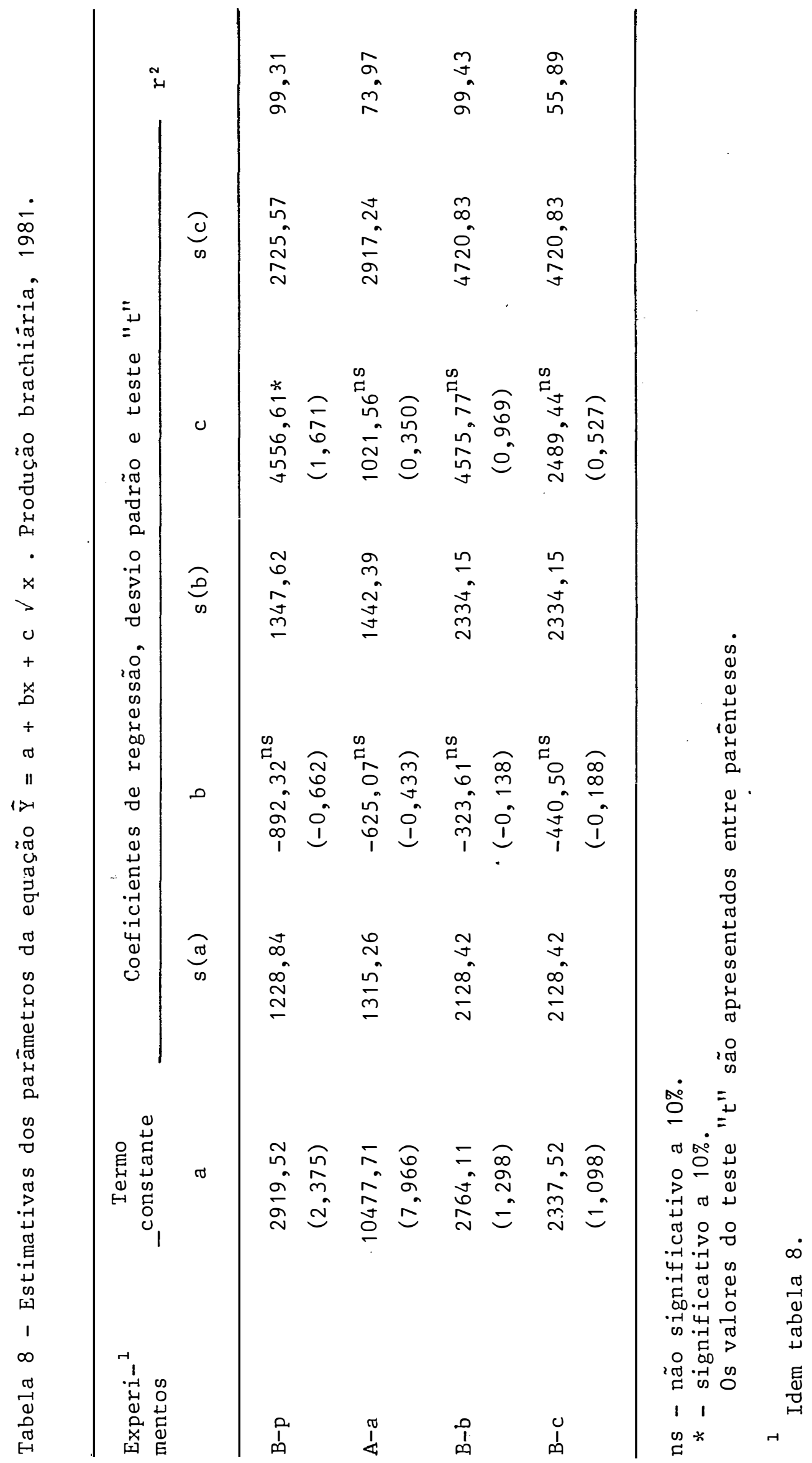


Nas Tabelas 30 a 35 do Apēndice 2, quando os efeitos de blocos, do nutriente e da época de plantio da brachiária foram levados em consideração, os valores de $\mathrm{r}^{2}$ aumen taram razoavelmente, o que nos leva a crer que outros fatores além do fósforo, foram responsáveis pela variação na produção. Com base nos indicadores de escolha, foram sele cionadas algumas funções para a análise econōmica. As funções, tanto quadrática como raiz quadrada, tiveram um ajustamento melhor com os dados de produção de brachiária do que com os de arroz. Deve-se ressaltar que com o critério de seleção adotado, tentou-se satisfazer os três indicadores de escolha citados anteriormente, porém, isto nem semprefoi possivel. As fun ções selecionadas para o arroz, não atendem aos trés critérios. Na maioria dos casos foram selecionadas apenas com base nos 'sinais dos coeficientes parciais da regressão. Como o ob-* jetivo do presente trabalho, é se fazer uma análise conjun ta, as funções selecionadas para a brachiária corresponderam aos mesmos casos das selecionadas. para o arroz, justificando - se deste modo a não inclusão de equações que apresentaram valores maiores para $r^{2}$ e melhor significāncia dos coeficientes parciais da regressão.

A seguir apresentamos as funções de resposta es colhidas para o arroz e brachiária: 
CASO 1:

$$
\begin{aligned}
& \bar{Y}_{A}(A-a)=688,23+323,76 x-56,34 x^{2} \\
& \bar{Y}_{B}(A-a)=10564,25+263,13 x-101,20 x^{2}
\end{aligned}
$$

CASO 2:

$$
\begin{aligned}
& \bar{Y}_{A}(B-b)=1949,54-142,76 x+121,40 \sqrt{x} \\
& \bar{Y}_{B}(B-b)=2764,11-323,61 x+4575,77 \sqrt{ } x
\end{aligned}
$$

CASO 3:

$$
\begin{aligned}
& \hat{Y}_{A}(B-c)=1581,88-135,50 x+458,17 \sqrt{x} \\
& \hat{Y}_{B}(B-c)=2337,52-440,50 x+2489,44 \sqrt{ } x
\end{aligned}
$$

CASO 4:

$$
\begin{aligned}
& \overline{\mathrm{Y}}_{A}(B-p)=1795,09-79,20 \mathrm{x}+142,99 \sqrt{ } \mathrm{x} \\
& \overline{\mathrm{Y}}_{B}(\mathrm{~B}-\mathrm{p})=2919,52-892,32 \mathrm{x}+4556,61 \sqrt{ } \mathrm{x}
\end{aligned}
$$

Para se calcular doses economicamente ótimas em ensaios de adubação, o ideal é que os níveis de adubo utiliza dos estejam no estágio racional de produção, como é chamado o segundo estágio de produção. Mas, saber qual o intervalo que corresponde ao estágio racional é muito dificil quando da ins talação do experimento. Nas Tabelas 9 e 10 , a seguir, vamos apresentar os valores esperados da produça do arroz ( $\left.\mathrm{Y}_{A}\right)$, da 
Tabela 9 - Produção esperada, produto médio, marginal e coeficiente de e lasticidade para o arroz, 1981.

\begin{tabular}{|c|c|c|c|c|c|}
\hline Experimentos ${ }^{1}$ & $\begin{array}{c}\text { Doses } \\
(\mathrm{x})\end{array}$ & $\begin{array}{c}\text { Produção } \\
\text { esperada } \\
\left(\mathrm{Y}_{\mathrm{A}}\right) \\
(\mathrm{em} \mathrm{kg} / \mathrm{ha})\end{array}$ & $\begin{array}{l}\text { Produto } \\
\text { médio } \\
\text { (kg/ha) }\end{array}$ & $\begin{array}{c}\text { Produto } \\
\text { marginal } \\
(\mathrm{kg} / \mathrm{ha})\end{array}$ & $\begin{array}{l}\text { Coeficiente } \\
\text { de elastici } \\
\text { dade }\end{array}$ \\
\hline \multirow{6}{*}{$A-a$} & 0 & 688,23 & - & - & - \\
\hline & 1 & 955,66 & 955,66 & 211,08 & 0,221 \\
\hline & 2 & 1110,40 & 555,20 & 98,40 & 0,177 \\
\hline & 2,87 & 1153,36 & 401.87 & 0,00 & 0,000 \\
\hline & 3 & 1152,45 & 384,15 & $-14,28$ & $-0,037$ \\
\hline & 4 & 1081,82 & 270,46 & $-126,96$ & $-0,469$ \\
\hline \multirow{6}{*}{ B-b } & 0 & 1949,54 & - & - & - \\
\hline & 0,18 & 1975,35 & 10974,17 & 0,00 & 0,000 \\
\hline & 1 & 1928,18 & $\cdot 1928,18$ & $-82,06$ & $-0,043$ \\
\hline & 2 & 1835,71 & 917,86 & $-99,84$ & $-0,109$ \\
\hline & 3 & 1731,53 & 577,18 & $-107,71$ & $-0,187$ \\
\hline & 4 & 1621,30 & 405,33 & $-112,41$ & $-0,277$ \\
\hline \multirow{6}{*}{$B-C$} & 0 & 1581,88 & - & - & - \\
\hline & 1 & 1904,56 & 1904,56 & 93,58 & 0,049 \\
\hline & 2 & 1958,83 & $979,42^{\circ}$ & 26,48 & 0,027 \\
\hline & 2,86 & 1969,19 & 688,53 & 0,00 & 0,000 \\
\hline & 3 & 1968,95 & 656,32 & $-3,24$ & $-0,005$ \\
\hline & 4 & 1956,22 & 489,06 & $-20,96$ & $-0,043$ \\
\hline \multirow{6}{*}{$B-p$} & 0 & 1795,09 & - & - & - \\
\hline & 0,81 & 1859,63 & 2295,84 & 0,00 & 0,000 \\
\hline & 1 & 1858,88 & 1858,88 & $-7,70$ & $-0,004$ \\
\hline & 2 & 1838,90 & 919,45 & $-28,64$ & $-0,031$ \\
\hline & 3 & 1805,15 & 601,72 & $-37,92$ & $-0,063$ \\
\hline & 4 & 1764,25 & 441,06 & $-43,45$ & $-0,099$ \\
\hline
\end{tabular}

a) $\hat{Y}_{A}(A-a)=688,23+323,76 x-56,34 x^{2}$

b) $\overline{\mathrm{Y}}_{\mathrm{A}}(\mathrm{B}-\mathrm{b})=1949,54-142,76 \mathrm{x}+121,40 \sqrt{\mathrm{X}}$

c) $\overline{\mathrm{Y}}_{\mathrm{A}}(\mathrm{B}-\mathrm{c})=1581,88-135,50 \mathrm{x}+458,17 \sqrt{\mathrm{x}}$

d) $\overline{\mathrm{Y}}_{A}(B-\mathrm{p})=1795,09-79,20 \mathrm{x}+142,99 \sqrt{\mathrm{x}}$

1 $A(07 / 10)$ e $B(27 / 10)$

$\mathrm{a}=10$ dias $; \mathrm{b}=20$ dias e $\mathrm{c}=30$ dias apös emergēncia

$\mathrm{p}=$ fōsforo. 
Tabela 10 - Produção esperada, produto médic, marginal e coeficiente de e lasticidade para a brachiāria, 1981.

\begin{tabular}{|c|c|c|c|c|c|}
\hline Experimento & $\begin{array}{c}\text { Doses } \\
(\mathrm{x})\end{array}$ & $\begin{array}{c}\text { Produção } \\
\text { esperada } \\
\left(\mathrm{Y}_{\mathrm{B}}\right) \\
(\text { em } \mathrm{kg} / \mathrm{ha})\end{array}$ & $\begin{array}{l}\text { Produto } \\
\text { médio } \\
(\mathrm{kg} / \mathrm{ha})\end{array}$ & $\begin{array}{c}\text { Produto } \\
\text { marginal } \\
(\mathrm{kg} / \mathrm{ha})\end{array}$ & $\begin{array}{l}\text { Coeficiente } \\
\text { de elastici } \\
\text { dade }\end{array}$ \\
\hline$A-a$ & $\begin{array}{c}0 \\
1 \\
1,3 \\
2 \\
3 \\
4\end{array}$ & $\begin{array}{r}10564,25 \\
10726,19 \\
10735,30 \\
10685,72 \\
10442,86 \\
9997,59\end{array}$ & $\begin{array}{c}- \\
10726,19 \\
8257,92 \\
5342,86 \\
3480,95 \\
2499,40\end{array}$ & $\begin{array}{r}- \\
60,73 \\
0,00 \\
-141,67 \\
-344,07 \\
-546,47\end{array}$ & $\begin{array}{r}- \\
0,006 \\
0,000 \\
-0,027 \\
-0,099 \\
-0,219\end{array}$ \\
\hline$B-b$ & $\begin{array}{c}0 \\
1 \\
2 \\
3 \\
4 \\
49,98\end{array}$ & $\begin{array}{r}2764,11 \\
7016,27 \\
8588,00 \\
9718,73 \\
10621,19 \\
18938,87\end{array}$ & $\begin{array}{r}- \\
701 \dot{b}, 27 \\
4294,00 \\
3239,58 \\
2655,30 \\
378,93\end{array}$ & $\begin{array}{r}- \\
1964,28 \\
1294,17 \\
997,30 \\
820,34 \\
0,00\end{array}$ & $\begin{array}{c}-\overline{-} \\
0,280 \\
0,301 \\
0,308 \\
0,309 \\
0,000\end{array}$ \\
\hline$B-C$ & $\begin{array}{c}0 \\
1 \\
2 \\
3 \\
4 \\
7,98\end{array}$ & $\begin{array}{l}2337,52 \\
4386,46 \\
4977,11 \\
5327,84 \\
5554,38 \\
5854,67\end{array}$ & $\begin{array}{r}- \\
4386,46 \\
2488,56 \\
1775,95 \\
1388,60 \\
733,67\end{array}$ & $\begin{array}{r}- \\
804,22 \\
439,65 \\
278,14 \\
181,86 \\
0,00\end{array}$ & $\begin{array}{c}- \\
0,183 \\
0,177 \\
0,157 \\
0,131 \\
0,000\end{array}$ \\
\hline$B-p$ & $\begin{array}{l}0 \\
1 \\
2 \\
3 \\
4 \\
6,51\end{array}$ & $\begin{array}{l}2919,52 \\
6583,81 \\
7578,90 \\
8134,84 \\
8463,45 \\
8736,56\end{array}$ & $\begin{array}{c}- \\
6583,81 \\
3789,45 \\
2711,61 \\
2115,86 \\
1342,02\end{array}$ & $\begin{array}{r}\dot{\overline{-}} \\
1385,99 \\
718,69 \\
423,06 \\
246,84 \\
0,00\end{array}$ & $\begin{array}{l}- \\
0,211 \\
0,190 \\
0,156 \\
0,117 \\
0,000\end{array}$ \\
\hline
\end{tabular}
a) $Y_{B}(A-a)=10564,25+263,13 x-101,20 x^{2}$
b) $\mathrm{Y}_{\mathrm{B}}(\mathrm{B}-\mathrm{b})=2764,11-323,61 \mathrm{x}+4575,77 \sqrt{\mathrm{x}}$
c) $\mathrm{Y}_{\mathrm{B}}(\mathrm{B}-\mathrm{c})=2337,52-440,50 \mathrm{x}+2489,44 \sqrt{\mathrm{x}}$
d) $Y_{B}(B-p)=2919,52-892,32 x+4556,61 \sqrt{ } x$
1
Idem tabela 10. 
produção de brachiária $\left(Y_{B}\right)$, produto médio (PMe), margïnal (FMa) e o coeficiente de elasticidade, para as funçoes escolhidas.

Convém ressaltar que estamos chamando de $x$, o número de doses do nutriente $\left(\mathrm{P}_{2} \mathrm{O}_{5}\right)$ utilizadas no ensaio, como também, o valor de $x$ que maximiza as referidas funçóes. Sen do $q$, a quantidade de $\mathrm{P}_{2} \mathrm{O}_{5}$ em quilogramas correspondente a uma dose, portanto, a quantidade do nutriente em kg/ha é dada por $\mathrm{x}=\mathrm{qx}$. No caso presente $\mathrm{q}=75 \mathrm{~kg}$ de $\mathrm{P}_{2} \mathrm{O}_{5}$.

As equações selecionadas relacionam as produções físicas do arroz e brachiária, que podem ser esperadas da utilização dos vários níveis do fertilizante (Tabelas 9 e 10). A terceira coluna da Tabela 9 (produção esperada), mostra que à medida que se aumenta a quantidade de $\mathrm{P}_{2} \mathrm{O}_{5}$, o rendimento fi sico do arroz, cresce a uma taxa decrescente, atinge um máximo e finalmente declina. Na Tabela 10 , para B-b; B-c e B-p, on de as doses de $\mathrm{P}_{2} \mathrm{O}_{5}$ que levam à máxima produção estão fora do limite do experimento, a produção esperada cresce a uma taxa decrescente.

o produto marginal de um insumo, mede o acrēscimo do produto total atribuível ao emprego de uma unidade adicional do insumo variável, sendo que os outros fatores são mantidos constantes. Observando-se as Tabelas 9 e 10 , podemos notar que o valor máximo da produção, ocorre no ponto em que o produto marginal do fator é igual a zero.

As Tabelas 9 e 10 contèm a produção esperada, produto médio, marginal e coeficiente de elasticidade para o 
arroz e brachiária respectivamente. Mas, no caso deste traba1ho, estamos diante de uma consorciação, portanto os dois pró dutos devem ser analisados conjuntamente.

Como se trata de dois produtos distintos, arroz e brachiária, è necessário transformá-los em valor monetạ rio antes de medir o efeito do nutriente sobre a produção. Pa rá tanto, bạsta definir a produção em termos de valor ou renda bruta. Assim:

$$
R B=\hat{Y}_{A} P_{A}+\hat{Y}_{B} P_{B}
$$

e a condição de primeira ordem para renda bruta máxima é:

$$
\frac{d}{d x}\left(\hat{Y}_{A} P_{A}+\hat{Y}_{B} P_{B}\right)=0
$$

ou

$$
\frac{d \bar{Y}_{A}}{d x} P_{A}+\frac{d \bar{Y}_{B}}{d x} \cdot P_{B}=0
$$

GOMINHO e MAFRA (1979), mostram que a máxima produção física conjunta ocorrerà quando:

$$
\frac{d \bar{Y}_{A}}{d x}+\frac{d \hat{Y}_{B}}{d x}=0
$$

mas, a condição de primeira ordem para que a renda bruta seja máxima (10) só dará origem à equação (11), quando o preço dos 
produtos forem iguais, ou seja, $P_{A}=P_{B}$, que não é muito provāvel de acontecer.

$$
\text { Aplicando-se a condição (10) em cada uma das } \underline{e}
$$
quações selecionadas anteriormente, pāgina 36, e utilizando -se os preços $\mathrm{P}_{\mathrm{A}}=\operatorname{Cr} \$ 28,75$ e $\mathrm{P}_{\mathrm{B}}=\operatorname{Cr} \$ 0,56$, que são os preços da época de instalação do experimento no campo (novembro de 1981), encontraremos a dose de $\mathrm{P}_{2} \mathrm{O}_{5}$ que determina a renda bruta máxima $\left(x_{R}\right)$. Estas doses estão apresentadas nas Tabelas 11 a 14

\subsection{Resultado econômico}

\subsubsection{Dose ótima econômica}

Lançando mão das funções de produção, dos preços dos produtos e do nutriente, podemos calcular com base nas expressões (7) para a quadrática e (8) para a raiz quadradar, as doses economicamente ótimas do nutriente, para os quatro casos selecionados. As Tabelas $11,12,13$ e 14 , apresentam o comportamento económico, retorno por hectare, para os cinco niveis de $\mathrm{P}_{2} \mathrm{O}_{5}$ estudados, como também a dose ótima ( $\left.\mathrm{x}^{\star}\right)$, a dose que torna máxima a produção de arroz $\left(\mathrm{x}_{\mathrm{A}}\right)$, de brachiāria $\left(\mathrm{x}_{\mathrm{B}}\right)$ e a dose que torna máxima a renda bruta $\left(x_{R}\right)$ com os preços mantidos constantes. 


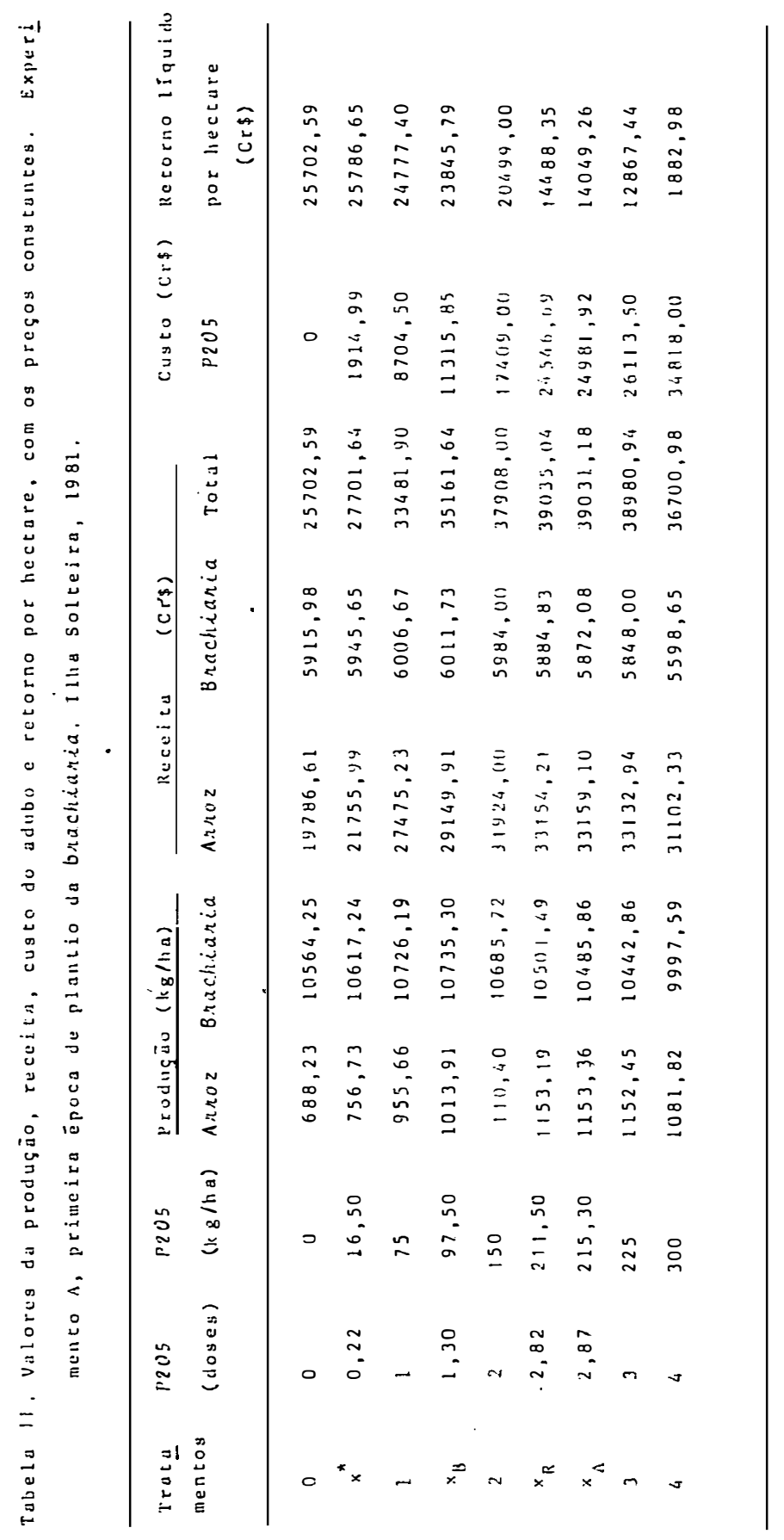




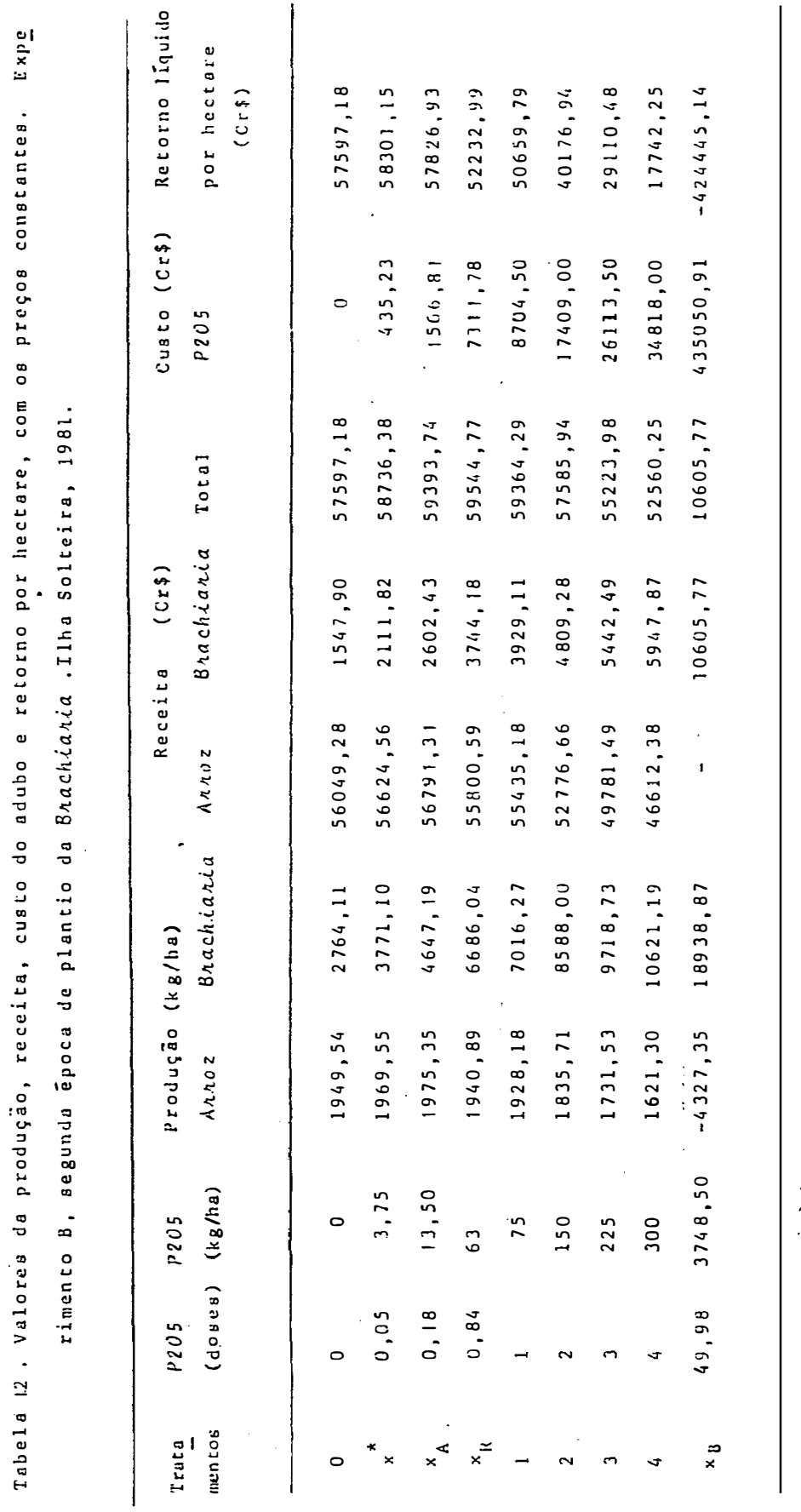




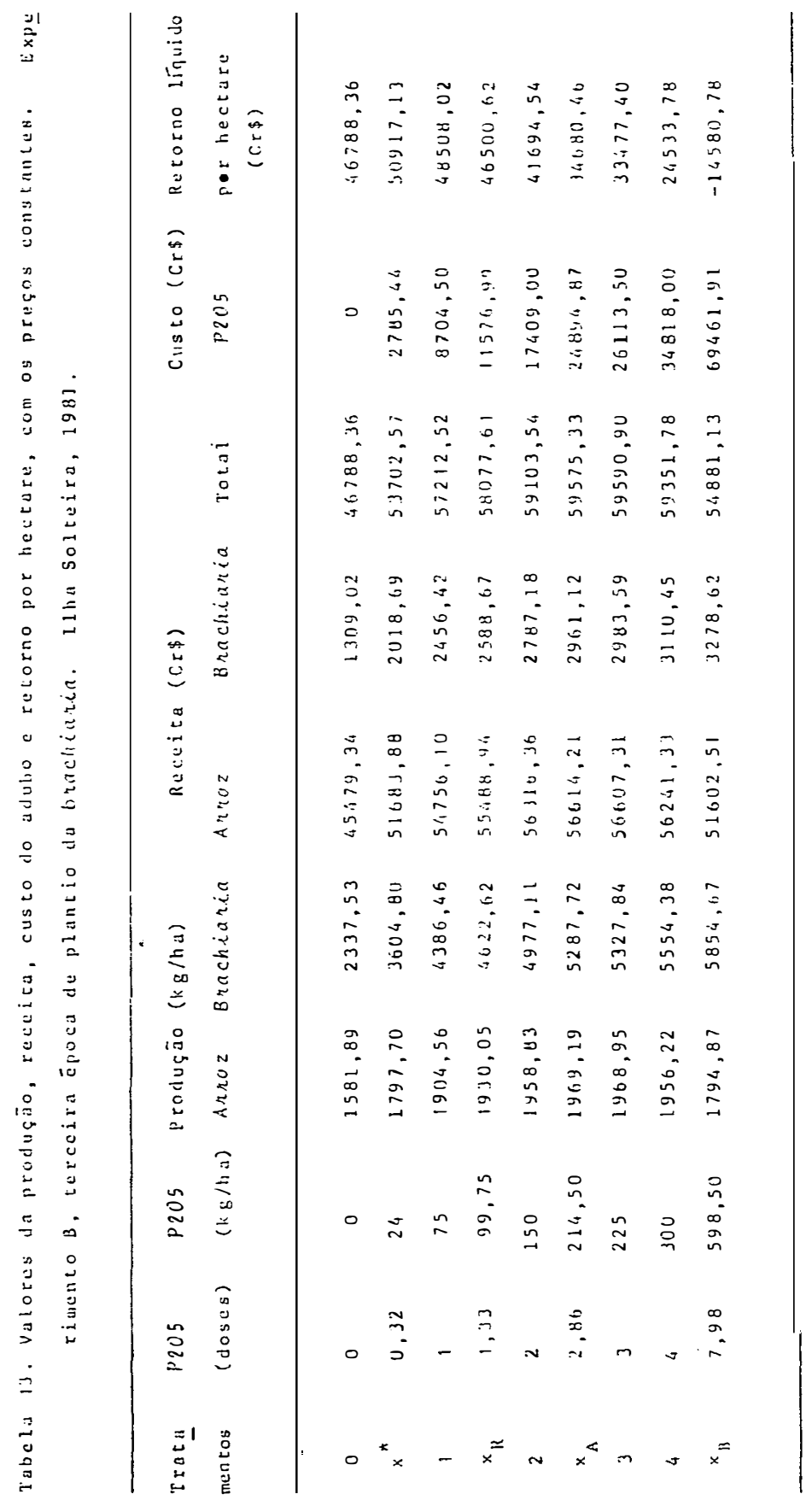




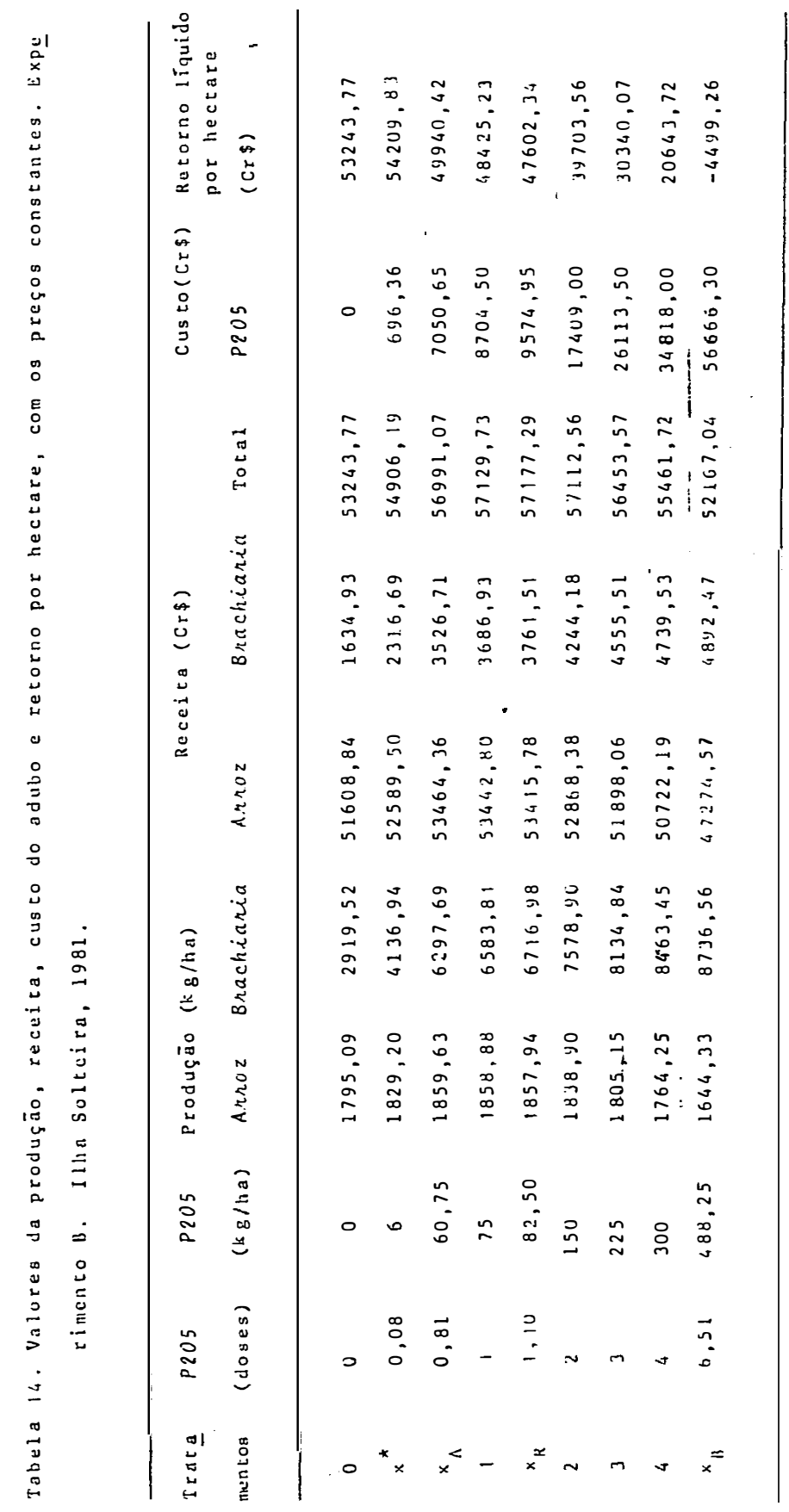


Comparando nestas tabelas as doses $x_{R}$ e $x_{A}$, no tamos que a dose $x_{R}$ está sempre próxima da $x_{A}$ (dose que maximiza a produção de arroz). Isto se deve ao fato de o arroz ter um peso maior por apresentar um preço cerca de 50 vezes o da brachiária. Isto mostra a importāncia da consorciação como fa tor de diminuição do custo de formação da pastagem.

\subsubsection{Demanda pelo insumo}

Ao analisarmos a demanda, vamos pressupor inicialmente que o agricultor compra o insumo e vende o produto em um mercado de concorrēncia perfeita. o empresärio maximiza dor de lucro aumentará o uso do insumo até que se atinja pon to onde o valor do produto marginal do insumo é exatamente igual ao preço do insumo, ou seja:

$$
\operatorname{VPMa} x=P x
$$

o valor do produto marginal de um insumo é definido como o aumento obtido na receita bruta da empresa qua do uma unidade adicional do insumo é utilizada na produção. Portanto, enquanto o acréscimo na receita bruta for maior do que o gasto adicional com o insumo variável, maiores quantida des do insumo devem ser utilizadas, com todas as outras condi ções da produção mantidas constantes, até que se atinja a con 
dição de māximo lucro (12).

Como neste trabalho temos dois produtos e um insumo, a condição (12) se torna:

$$
\mathrm{VPMa}_{\mathrm{x}(\mathrm{A})}+\mathrm{VPMa}_{\mathrm{x}}(\mathrm{B})=\mathrm{P}_{\mathrm{x}}
$$

como o valor do produto marginal é definido como o resultado da produtividade marginal ( $f_{A}$ ou $f_{B}$ ), multiplicada pelo preço do produto $\left(\mathrm{P}_{A}\right.$ ou $\left.\mathrm{P}_{B}\right)$, temos que:

$$
P_{A} f_{A}+P_{B} f_{B}=P_{x}
$$

onde $\mathrm{P}_{\mathrm{A}} \mathrm{f}_{\mathrm{A}} \mathrm{e}$ o valor do produto marginal de $\mathrm{P}_{2} \mathrm{O}_{5}$ para o arroz e $\mathrm{P}_{\mathrm{B}} \mathrm{f}_{\mathrm{B}} \mathrm{e}$ o valor do produto marginal de $\mathrm{P}_{2} \mathrm{O}_{5}$ para a brachia ria.

Sabemos da teoria económica, que a curva de de manda para um fator variável é a própria curva do valor do pro duto marginal do serviço produtivo em questão ${ }^{3}$. Com os preços dos produtos mantidos constantes, unidades de $\mathrm{P}_{2} \mathrm{O}_{5}$ são acrescidas enquanto o valor do produto marginal exceder o preço do insumo, pois se continuarmos a aumentar quantidades de $\mathrm{P}_{2} \mathrm{O}_{5} \underline{a}$ lém do ponto onde $\mathrm{VPMa}=\mathrm{P}_{\mathrm{x}}$, estaremos aumentando mais o custo total do que a receita total.

$$
\text { Para que o agricultor se interesse em aplicar }
$$
maiores quantidades de $\mathrm{P}_{2} \mathrm{O}_{5}$, o preço do fertilizante deveria

1 FERGUSON (1981) . p.400. 
ser reduzido, porque quanto menor o custo do insumo, maior a quantidade procurada, isto é o que diz a própria lei da procu ra. Mas fica mais dificil de se analisar os efeitos de mudan ças nos preços dos produtos $\left(\mathrm{P}_{A}\right.$ e $\left.\mathrm{P}_{\mathrm{B}}\right)$. Para isto será preciso mudarmos as pröprias curvas de demanda.

A Figura 1 sintetiza toda essa discussão sobre o assunto.

A curva de demanda pelo adubo é a linha DD', proveniente da soma do valor dos produtos marginais do adubo para arroz e brachiária, enquanto que a linha horizontal, ao preço de $\mathrm{P}_{2} \mathrm{O}_{5}$ dominante, representa a própria curva de oferta deste insumo para o agricultor.

A ärea hachuriada representa para o produtor, o custo do adubo (área retangular) e o lucro (área triangular). 


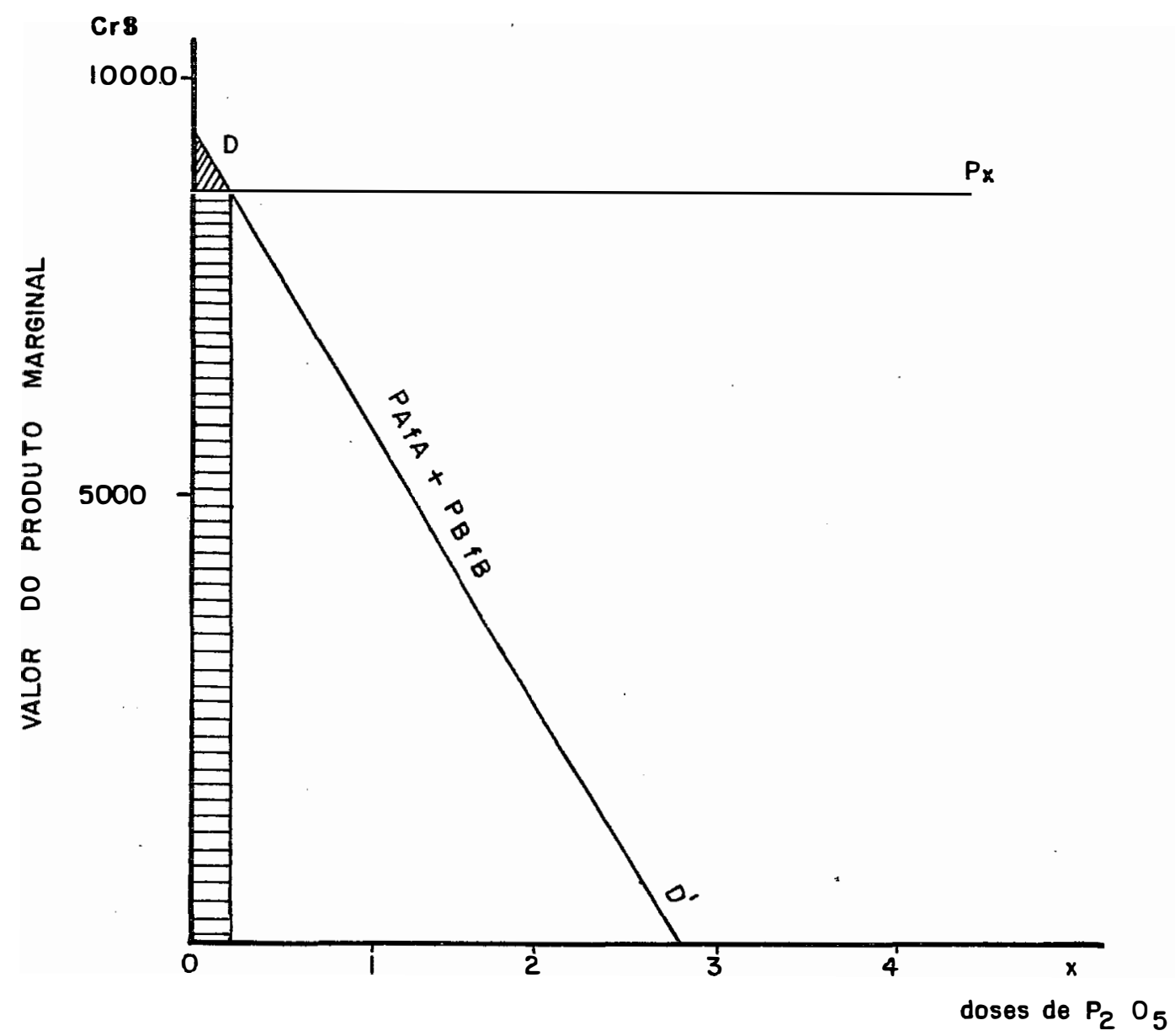

Figura 1 - Curvas de demanda e oferta de $\mathrm{P}_{2} \mathrm{O}_{5}$ para o produtor.

4.3.3. Análise da variação dos preços

As recomendações de dose ótima econômica apresentadas até aqui, pressupõem preços constantes de insumo e produtos, porém na prática isto geralmente não ocorre. Se hou 
ver variações nos preços estas quantidades ótimas do insumo po dem sofrer alterações substanciais.

Vimos que os preços apresentados foram para o arroz $\mathrm{PY}_{\mathrm{A}}=\operatorname{Cr} \$ 28,75 \circ \mathrm{kg} ;$ para a pastagem $\mathrm{PY}_{\mathrm{B}}=\operatorname{Cr} \$ 0,56 \circ$ $\mathrm{kg}$ e para ofósforo $\mathrm{P}_{\mathrm{X}}=\operatorname{Cr} \$ 8704,50$ a dose de $\mathrm{P}_{2} \mathrm{O}_{5}$, que são os preços de novembro de 1981, época da instalação do experimento em campo. A Tabela 15 a seguir, traz uma variação nestes preços de 50\% acima e abaixo daqueles niveis.

Tabela 15 - Variações nos preços dos produtos e insumo.

\begin{tabular}{lccc}
\hline & \multicolumn{3}{c}{ Preços } \\
\cline { 2 - 4 } Componentes & Normal & $\begin{array}{c}\text { Diminu ição de } \\
50 \%\end{array}$ \\
\hline $\mathrm{PY}_{\mathrm{A}}(\mathrm{Cr} \$ / \mathrm{kg})$ & 43,13 & 28,75 & 14,38 \\
$\mathrm{PY}_{\mathrm{B}}(\mathrm{Cr} \$ / \mathrm{kg})$ & 0,84 & 0,56 & 0,28 \\
$\mathrm{P}_{\mathrm{X}}(\operatorname{Cr} \$ /$ dose $)$ & 13056,75 & 8704,50 & 4352,25 \\
\hline
\end{tabular}

Nas Tabelas 16 a 19 são apresentadas värias al ternativas obtidas de algumas combinações destes preços, partindo da alternativa (1), que contém os preços normais para os produtos e insumo, ou seja, os preços de novembro de 1981. Com base nestas várias situações de preços, foram calculadas as quantidades ótimas de $\mathrm{P}_{2} \mathrm{O}_{5}$ em kg/ha, alēm do rendimento fi sico dos dois produtos e do retorno liquido por hectare. 


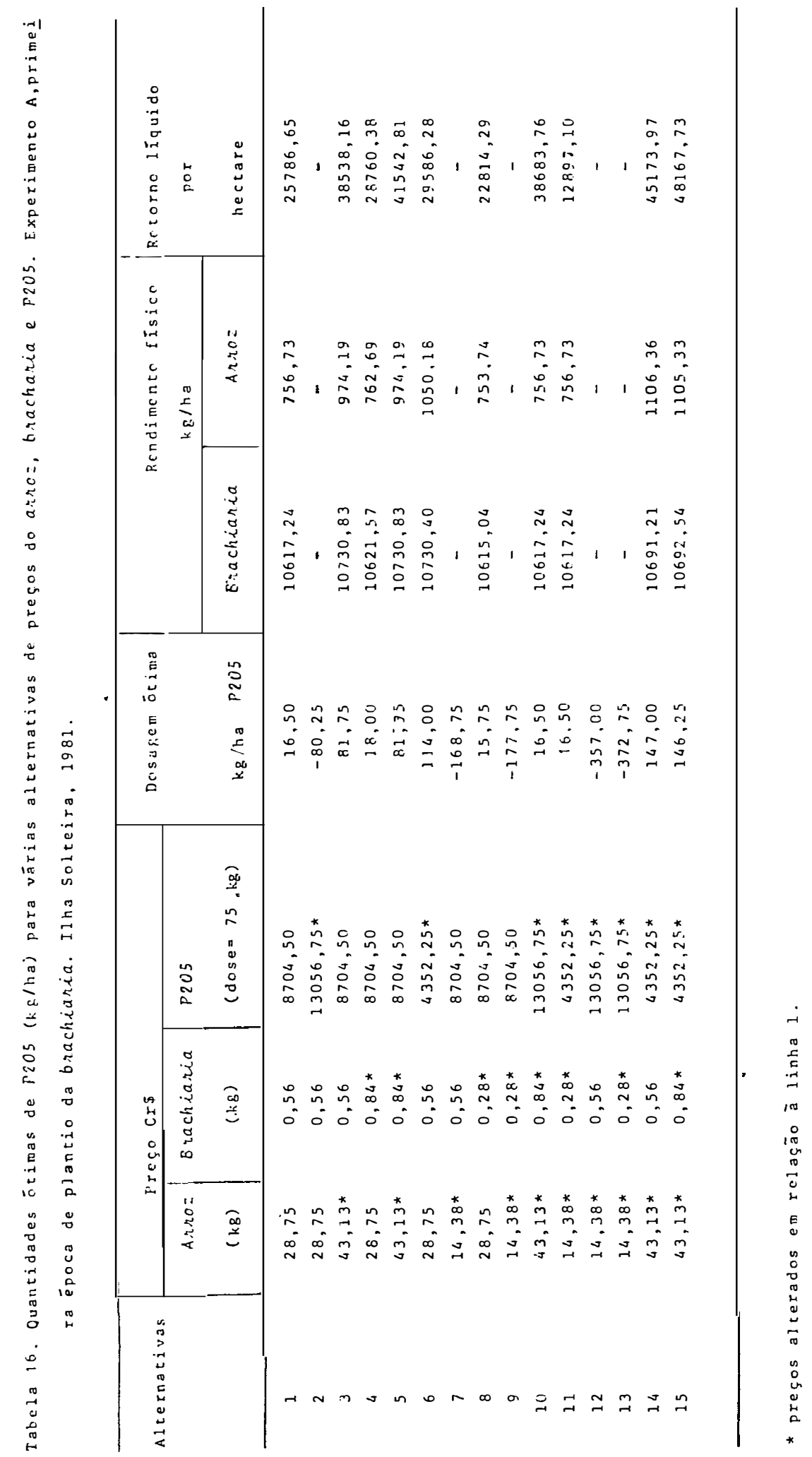




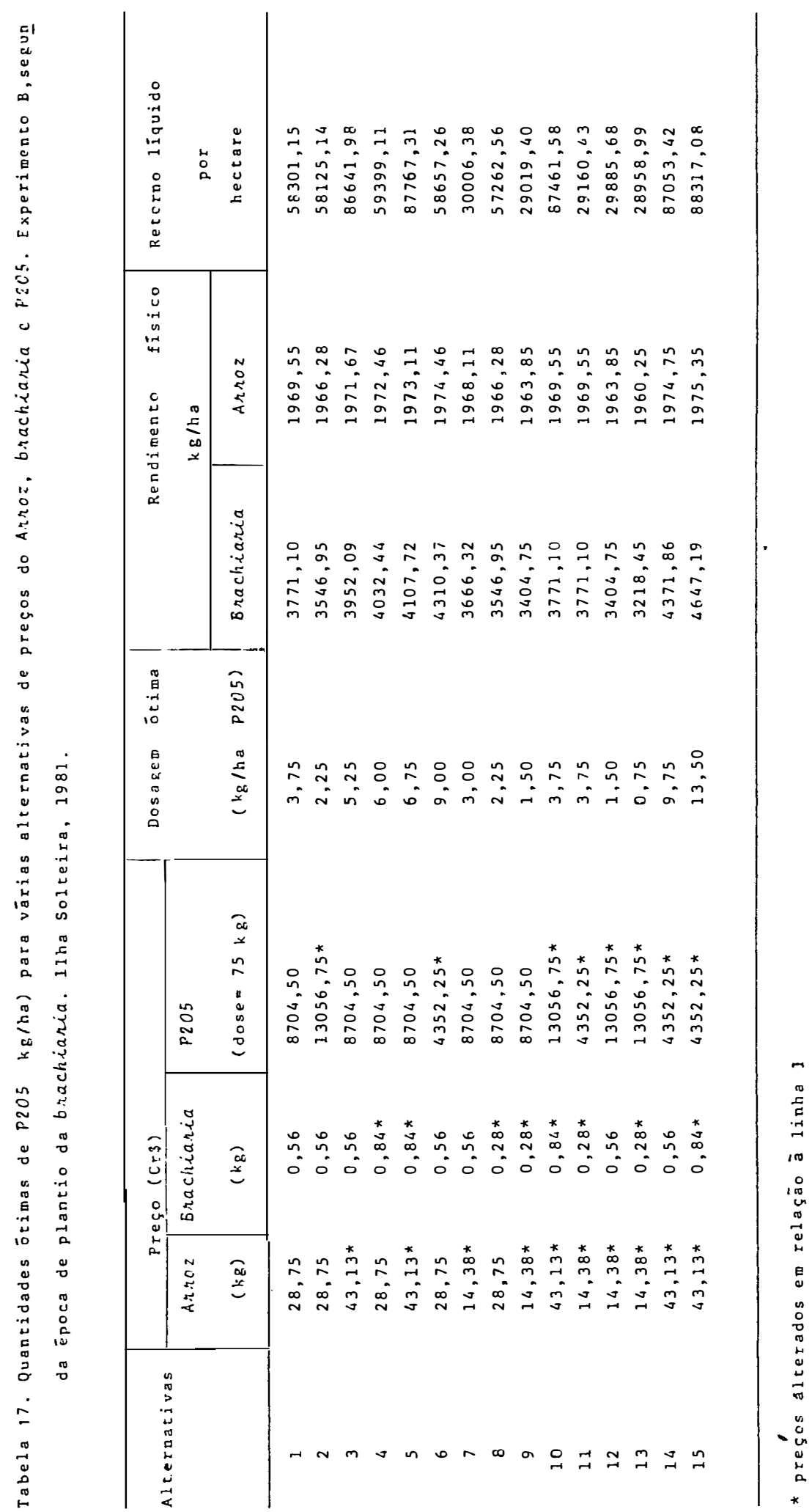




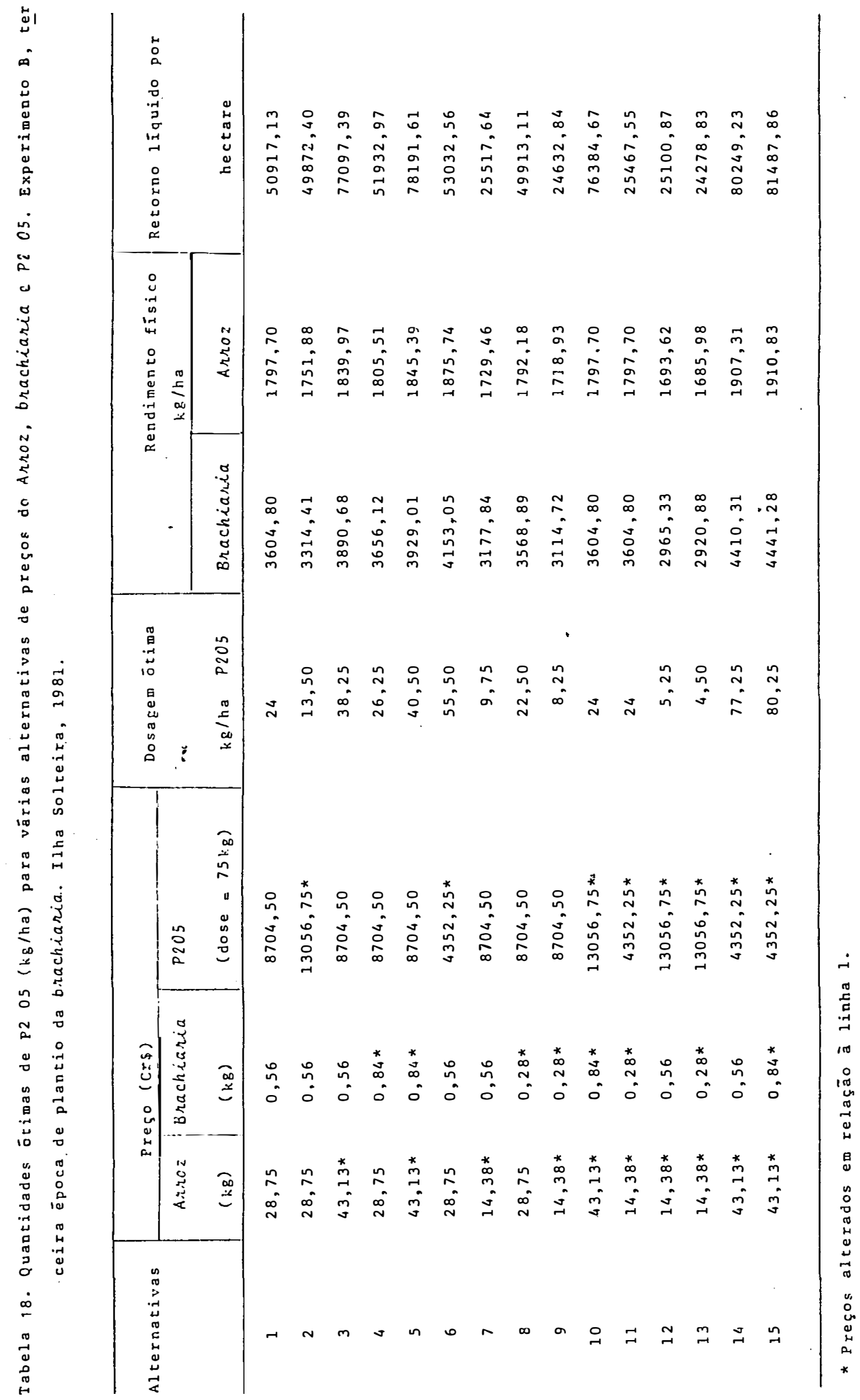


.54.

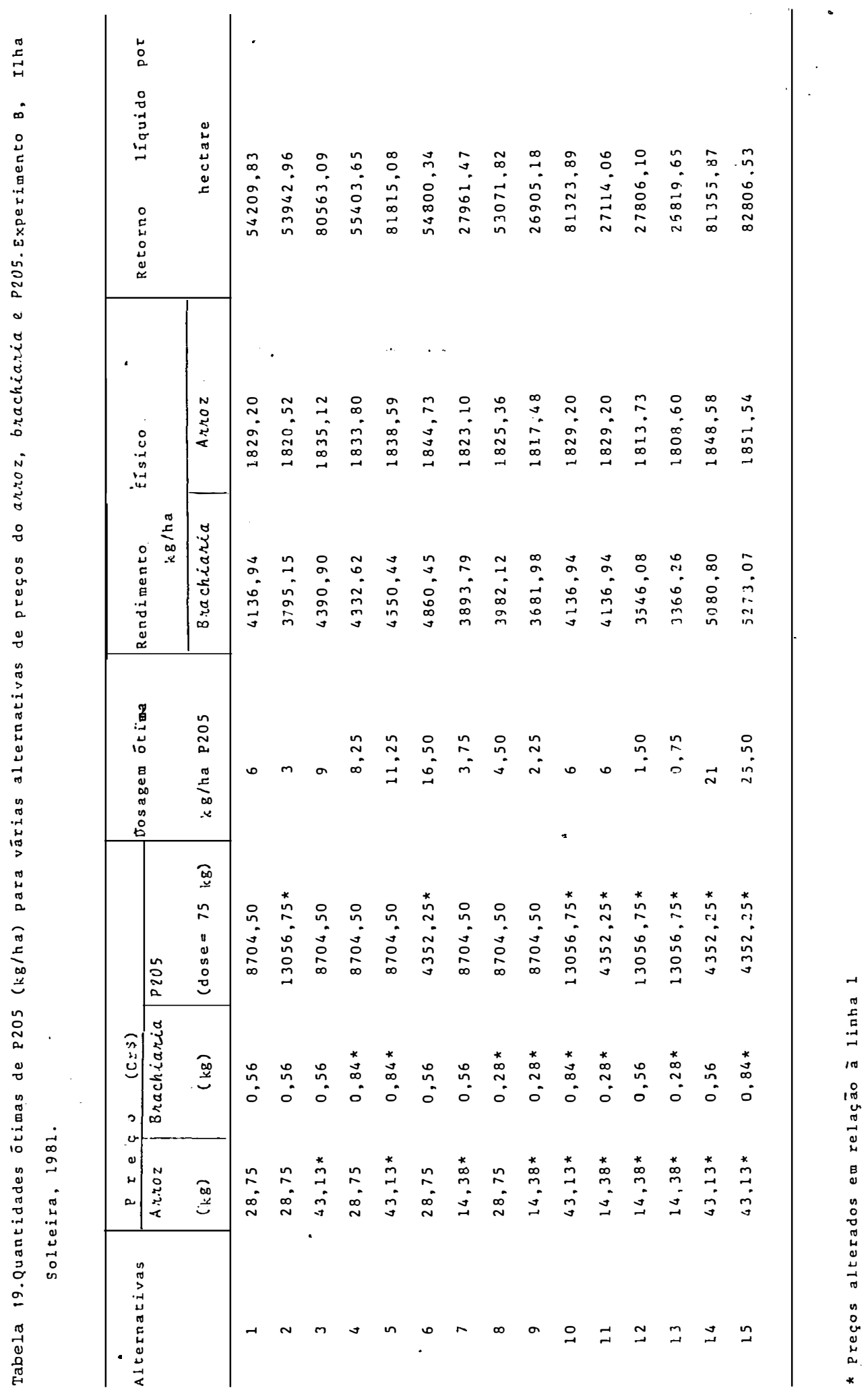


A última coluna destas tabelas, mostra que o retorno liquido por hectare varia em função dos preços do arroz (alternativas 3 e 7), da brachiāria (alternativas 4 e 8 ), de ambos (alternativas 5 e 9) e do preço do insumo (alternativas 2 e 6 ).

Caso o preço do insumo seja reduzido em $50 \%$, mantidos constantes os preços dos produtos, a quantidade ótima de $\mathrm{P}_{2} \mathrm{O}_{5}$ e o retorno por hectare aumentaram (alternativa 6). o contrário ocorre quando o preço do insumo sofre um aumento (alternativa 2).

Caso os preços do arroz, brachiária e $\mathrm{P}_{2} \mathrm{O}_{5}$ aumentarem ou diminuírem na mesma proporção, a dosagem ótima não se altera e $\dot{o}$ retorno líquido por hectare aumenta ou diminui na mesma proporção (alternativas 10 e 11 respectivamente).

Vamos analisar os dois extremos possiveis de $\underline{a}$ contecer com os preços. A mais otimista das hipóteses para o produtor ocorreria se os produtos tivessem seus preços aumentados de $50 \%$ com o preço do insumo diminuindo da mesma porcen tagem, neste caso, o retorno liquido seria o máximo possível e haveria interesse em utilizar quantidades razoáveis do adubo (alternativa 15). A hipótese mais pessimista ocorreria caso o preço dos produtos sofressem uma diminuição de $50 \%$ e o insumo tivesse seu preço aumentado dessa porcentagem. A quantidade de adubo a ser usada neste caso seria irrisória, ou me mo zero, obtendo deste modo, o menor retorno liquido para estas relações de preços utilizadas (alternativa 13). 
As diferenças nas recomendações de adubaçãones tes dois casos extremos são bastante grandes. Por isso, sagn do SCHUH e TOLLINI (1972), não faz sentido falar sobre uma re comendação nessas circunstāncias. A recomendação correta depende do que o agricultor tem que pagar pelo fertilizante e do que ele espera receber pelo seu produto.

4.3:4. Determinação da melhor época de plantio da brachiária

Com a finalidade de se determinar a melhor épo ca de plantió da brachiāria, utilizou-se da função de resposta que contém o efeito de blocos (B), fósforo (P) e época de plantio da brachiāria (E), cujas estimativas dos parāmetros estão apresentadas nas Tabelas 30 a 32 do Apéndice 2. Como que remos determinar a melhor época de plantio da brachiāria, bas ta para isto derivar a função em relação à época e igualar a zero. Utilizou-se a dose média de $\mathrm{P}_{2} \mathrm{O}_{5}$, que é $150 \mathrm{~kg} / \mathrm{ha}$.

A equação usada foi:

$$
\begin{aligned}
\mathrm{Y}_{\mathrm{A}}= & -871,77 \mathrm{~B}_{1}-334,11 \mathrm{~B}_{2}-450,43 \mathrm{~B}_{3}-97,36 \mathrm{P}+1013,84 \mathrm{E}+ \\
& +39,21 \mathrm{P}^{2}-310,06 \mathrm{E}^{2}+49,04 \mathrm{EP}
\end{aligned}
$$

Apenas esta função que é relativa à produção de arroz do primeiro experimento $(07 / 10 / 81)$, apresentou como resultado uma época coerente com as usadas no experimento. 0 i- 
deal neste caso, é que o plantio da brachiáría se realize aos 13 dias após a emergéncia do arroz. 


\section{CONCLUSÕES}

Pelos resultados obtidos pode-se concluir que: $\vdots$

(a) A quantidade de $\mathrm{P}_{2} \mathrm{O}_{5}$ a ser recomendada variou de 4 a $24 \mathrm{~kg}$ por hectare, para preços iguais aos correntes na época de instalação dos ensaios (novembro de 1981), devendo-se res saltar que este é um valor relativamente baixo dadas as caracteristicas dos solos de regiões de cerrado serem pobres em fósforo.

(b) As produções do arroz e da pastagem foram bem superiores nos experimentos $A$ e B, instalados no més de outubro, o que sugere que o plantio deva ser realizado entre 07 e 27 de outubro. 
(c) Com base nas produções físicas obtidas, conclui-se que a pastagem deva ser semeada nas entrelinhas do arroz, de 10 a 20 dias após sua emergēncia, entretanto quando se consi dera o valor total da produção (quantidade x preço), percebe-se que a melhor época deve ser de 20 a 30 dias.

(d) Quando utilizou-se a função de resposta que leva em consí deração além do fósforo, o efeito de blocos e de época de plantio da brachiária obteve-se que a pastagem deva ser semeada 13 dias após a emergéncia do arroz. Esta conclusão só é válida para o experimento $A(07 / 10 / 81)$, pois nos outros dois experimentos a época encontrada se situava fora dos $1 \underset{\dddot{m}}{i m i t e s}$ estabelecidos no experimento.

\section{LIMITAÇÕES DO ESTUDO}

Pelas próprias características do trabalho, ou seja, a implantação de pastagem, a anälise deveria ser realiza da com dados de produção da brachiária para mais de um ano, o que daria um subsídio maior na interpretação dos resultados.

Outro fator que deve ser considerado é quanto à determinação da melhor época de plantio do arroz. Para uma maior segurança, o experimento como um todo deveria ser repetí do mais de uma vez. 
.60 .

\section{LITERATURA CITADA}

Costa, R.A. da, 1977. Funções de Produção Ajustadas'a Ensaios Fatoriais $: 3^{3}$ de Adubação de Arroz. Piracicaba, ESALQ/USP, 80p. [Dissertação de Mestrado].

CRUZ, E.R. da, 1975. Anälise Económica de Experimentos Usando Função de Produção Quadrática: Exemplo Simples e Didático do Uso de Fertilizantes na Cultura do Trigo. Brasilia, EMBRAPA-DDM, 32p. [Mimeografado] .

EMBRAPA, Brasilia, 1979. Relatōrio Técnico Anual do Centro de Pesquisa de Gado de Corte 1976. 120p.

FERGUSON, C.E., 1981. Microeconomia. 4ed. rev. Rio de Janeiro, Forense-Universitäria. $610 \mathrm{p}$. 
GOMINHO, M.S.F. e R.C. MAFRA, 1979. Uma Metodologia de Aná1 ise Agroeconómica para Culturas Consorciadas em Experimentos de Adubação. Pesquisa Agropecuária Pernambucana. Recife, $\underline{3}(2): 161-182$.

JARDIM, W.R., 1976. Alimentos e Alimentação do Gado Bovino. São Paulo, Editora Agronómica Ceres. 338 .

KORNELIUS, E.; M.G. SAUERESSIG e W.J. GOEDERT, 1982. Estabelecimento e Manejo de Pastagens nos. Cerrados do Brasil. In: TERGAS, L.E.; P.A. SANCHEZ e E.A.S. SERRÃO. Produção de Pastagens em Solos Ācidos dos Trópicos. Brasilia, Editerral /EMBRAPA / CIAT , p. 167-187.

LANZER, E.A., 1970. Análise Económica de um Grupo de Experimentos de Fertilização e Calagem do Solo na. Cultura do Trigo. Porto Alegre, IEPE/UFRS, 117p. [Tese de Mestrado]. 
LESSINGER, E., 19?2. Análise Econömica do Efeito Residual do Fósforo e do Calcário num Experimento com Pastagem e Trigo através de Funções de Produção. Vacaria, RS, 1965/1970. Porto Alegre, IEPE/UFRS, 105p. [Tese de Mestrado].

LIMA, L.A. de P., 1979. Anảlise Agroeconōmica da Adubação NPK de Diferentes Populações de Milho, em dois Solos do Triāngulo Mineiro. Viçosa, UFV, 77p. [Tese de Doutoramento].

MENEGUELLI, C.A. e H. TOLLINI, 1978. O Problema da Forma Algébrica de Funções de Resposta a Fertilizantes. Revista de Economia Ŕural. Brasilia, 16(4): 97-104.

NOVAIS, R.F. e B.V. DEFELIPO, 1971. Niveis ótimos de NPK, na Adubação de Arroz "de Sequeiro", em um Solo de Cerrado de Patos de Minas. Experientiae. Viçosa, 11(7): 281-296.

PORTO, V.H. da F., 1980. Anālise Econométrica de Dados Experimentais Sobre um Sistema de Producão Trigo-Soja, para a Cultura de Trigo. Piracicaba, ESALQ/USP, 109p. [Dissertação de Mestrado].

SÃO PAUlo. Secretaria da Agricultura. Instituto de Economia Agricola, 1981. Informações Econömicas. São Paulo, 11(12): 70. 
SÃO PAUlo. Secretaria da Agricultura. Instituto de Economia Agricola, 1982. Informações Económicas. São Paulo, 12(1): 86.

SÃO PAULO. Secretaria da Agricultura. Instituto de Economia Agrícola, 1982. Informações Econōmicas. São Paulo, $12(3)$ : 76.

SCHUH, G.E..e H. TOLLINI, 1972. Anālise Conjunta de Ensaios de Adubação. Brasilia, Ministério da Agricultura, EAPA/ / SUPLAN, 44p. [Mimeografado].

SILVA, P.R. „̋ 1967. Análise Econömica do Emprego de Fertilizante na Cultura do Feijoeiro, através da Função de Produção - Zona da Mata, MG. Viçosa, UFV, 61p. [Tese de Mestrado ]

Stefanelo, E.L., 1975. Anālise Económica e Relação Técnica entre o Rendimento da Soja e o Emprego de Fertilizantes e Calcário em Dez Locais do Rio Grande do Sul. Porto Alegre, IEPE/UFRS, 149p. [Tese de Mestrado].

TEIXEIRA, T.D.; F.R. GOMES; J.D. GALVÃO; H. TOLLINI e L.M. de MOURA, 1971. Análise Agroeconómica de Experimentos de Milho Realizados em Capinópolis e Sete Lagoas, Minas Gerais, através da Função de Produção. Experientiae. Viçosá, 11(2): 45-134. 
VALDÉS, A.E., 1967. Analisis Economico de 20 Ensayos de Aplicación de Fertilizantes en Trigo, Maiz e Papas. In: MONTERO, E.B. e S.V. PERES. Investigación Economica y Experimentación Agricola. Montevideo, OEA. Instituto Interamericano de Ciēncias Agricolas, p.79-129.

VIEIRA, S., 1970. Aspectos das Funções de Produção Ajustadas aos Ensaios Fatoriais $3^{3}$ de Adubação. Piracicaba, ESALQ/ /USP, 165p. [Tese de Doutoramento].

VIEIRA, S.; H.V. de ARRUDA e R. HOFFMANN, 1971. Estudo Comparativo de Très Funções na Anālise Econométrica de Experimentos de Adúbação. Piracicaba, ESALQ/USP. Departamento de Ciēncias Sociais Aplicadas, $111 \mathrm{p}$.

WONNACOTT, R.J. e T.H. WONNACOTT, 1976. Econometria. Rio de Janeiro, Livros Técnicos e Científicos Editora S.A. $\quad 464$. 
.65.

$\begin{array}{llllllll}\text { A } & \mathbf{P} & \overline{\mathrm{E}} & \mathbf{N} & \mathbf{D} & \mathbf{I} & \mathbf{C} & \mathbf{E}\end{array}$ 
o preço correspondente a um $\mathrm{kg}$ de massa verde da pastagem em questão foi calculado, usando-se o valor médio da quantidade de matéria seca existente nesta pastagem. Este valor, de $24,23 \%$, foi obtido a partir de análises desta pastą gem realizada pelo Laboratório de Nutrição Animal da UNESP, de Ilha Solteira.

Utilizando-se da tabela fornecida por JARDIM, onde uma vaca adulta com $400 \mathrm{~kg}$ de peso vivo, seca ou em gestação, consome $6,4 \mathrm{~kg}$ de matéria seca por dia, calculou-se a quantidade de massa verde consumida por cabeça por dia $(26,41$ kg de pastagém/cabeça/dia).

o valor do aluguel do pasto por cabeça por més, obtido de "Informações Econōmicas" para a DIRÄ de Araçatuba foi, para novembro de $1981, \operatorname{Cr} \$ 443,00$ ou $\operatorname{Cr} \$ 14,77$ por animal e por dia.

A partir destes dados, calculou-se o valor do kg de brachiāria, que foi de $\operatorname{cr} \$ 0,56$. 


\section{APÊNDICE 2}

Tabela 20 - Análise de variância para a cultura do arroz. Experimento A $(07 / 10 / 81)$.

\begin{tabular}{|c|c|c|c|c|c|}
\hline $\begin{array}{l}\text { Causas de } \\
\text { variação }\end{array}$ & & G.L. & SQ & $\mathrm{QM}$ & $\mathrm{F}$ \\
\hline Blocos & & 3 & 5829926 & 1943308 & $6,16 \div$ \\
\hline $\mathrm{P}_{2} \mathrm{O}_{5}$ & . & 4 & 5544994 & 1386248 & $4,40 *$ \\
\hline $\operatorname{Erro}(a)$ & & 12 & 3784792 & 315399 & - \\
\hline Parc. & & 19 & 15159712 & & \\
\hline$\overline{E^{1}}$ & & 2 & 10956406 & 5478203 & $11,60 \div$ \\
\hline $\operatorname{ExP}$ & & 8 & 5145084 & 643135 & $1,36^{\mathrm{ns}}$ \\
\hline $\mathrm{EdP}_{1}$ & $\because$ & 2 & 2452127 & 1226062 & $2,59^{n s}$ \\
\hline $\mathrm{EdP}_{2}$ & & 2 & 5157876 & 2578938 & $5,46 * *$ \\
\hline $\mathrm{EdP}_{3}$ & & 2 & 554116 & 277058 & $0,59^{\mathrm{ns}}$ \\
\hline $\mathrm{EdP}_{4}$ & & 2 & 2649829 & 1324914 & $2,80^{\mathrm{ns}}$ \\
\hline $\mathrm{EdP}_{5}$ & & 2 & 5287543 & 2643771 & $5,60 \div$ \\
\hline $\mathrm{PdE}_{1}$ & & 4 & 1401147 & 350286 & $0,83^{\mathrm{ns}}$ \\
\hline $\mathrm{PdE}_{2}$ & & 4 & 5637362 & 1409340 & $3,35 \div$ \\
\hline $\mathrm{PdE}_{3}$ & & 4 & 3651567 & 912891 & $2,17^{\mathrm{ns}}$ \\
\hline Erro(b) & & 30 & 14174410 & 472480 & - \\
\hline Total & & 59 & 45435613 & - & - \\
\hline
\end{tabular}

$1 \mathrm{E}=$ época de plantio da brachiāria Niveis de significāncia: $5 \%(\stackrel{*}{*})$ e $1 \%(* *)$ ns - não significativo a $5 \%$

C.V. $=43,15$ 
Tabela 21 - Anālise de variāncia para a cultura do arroz. Experimento B $(27 / 10 / 81)$.

\begin{tabular}{|c|c|c|c|c|}
\hline $\begin{array}{l}\text { Causas de } \\
\text { variação }\end{array}$ & G.L. & S.Q. & Q.M. & $\mathrm{F}$ \\
\hline Blocos & 3 & 3399751 & 1133250 & $5,06 *$ \\
\hline $\mathrm{P}_{2} \mathrm{O}_{5}$ & 4 & 833415 & 208353 & $0,93^{\mathrm{ns}}$ \\
\hline Erro(a) & 12 & 2690330 & 224194 & - \\
\hline Parc. & 19 & 6923497 & - & - \\
\hline$E^{1:}$ & 2 & 153954 & 76977 & $0,29^{\mathrm{ns}}$ \\
\hline ExP & 8 & 805075 & 100634 & $0,38^{\mathrm{ns}}$ \\
\hline $\mathrm{EdP}_{1}$ & 2 & 298155 & 1.49077 & $0,56^{\mathrm{ns}}$ \\
\hline $\mathrm{EdP}_{2}$ & 2 & 60312 & 30156 & $0,11^{\mathrm{ns}}$ \\
\hline $\mathrm{EdP}_{3}$ & 2 & 216908 & 108454 & $0,41^{\text {ns }}$ \\
\hline $\mathrm{EdP}_{4}$ & 2 & 88128 & 44064 & $0,17^{\mathrm{ns}}$ \\
\hline $\mathrm{EdP}_{5}$ & 2 & 295524 & 147762 & $0,56^{\mathrm{ns}}$ \\
\hline $\mathrm{PdE}_{1}$ & 4 & 194152 & 48538 & $0,19^{\mathrm{ns}}$ \\
\hline $\mathrm{PdE}_{2}$ & 4 & 610597 & .152649 & $0,61^{\mathrm{ns}}$ \\
\hline $\mathrm{PdE}_{3}$ & 4 & 833741 & 208435 & $0,83^{\mathrm{ns}}$ \\
\hline Erro(b) & 30 & 7935942 & 264531 & - \\
\hline Total & 59 & 15818470 & - & - \\
\hline
\end{tabular}

I $\mathrm{E}=$ época de plantio da brachiāria.

Nível de significância: $5 \%(\stackrel{\star}{*})$

ns - não significativo a $5 \%$

$\mathrm{C} . \mathrm{V} \cdot=28,38$ 
Tabela 22 - Análise de variāncia para a cultura do arroz. Experimento C $(16 / 11 / 81)$.

\begin{tabular}{|c|c|c|c|c|c|}
\hline $\begin{array}{l}\text { Causas de } \\
\text { variação }\end{array}$ & & G.L. & S.Q. & Q.M. & $\mathrm{F}$ \\
\hline Blocos & & 3 & 452353 & 150784 & $11,18 \div$ \\
\hline $\mathrm{P}_{2} \mathrm{O}_{5}$ & & 4 & 135783 & 33945 & $2,52^{\mathrm{ns}}$ \\
\hline Erro(a) & & 12 & 161828 & 13485 & - \\
\hline Parcelas & & 19 & 749964 & - & - \\
\hline $\mathrm{E}^{1}$ & & 2 & 618789 & 309394 & $24,68 \div$ \\
\hline ExP & & 8 & 49122 & 61403 & $0,49^{\mathrm{ns}}$ \\
\hline $\mathrm{EdP}_{1}$ & & 2 & 47317 & 23658 & $1,89^{\mathrm{ns}}$ \\
\hline $\mathrm{EdP}_{2}$ & & 2 & 86143 & 43071 & $3,44 *$ \\
\hline $\mathrm{EdP}_{3}$ & $\because$ & 2 & 232565 & 116282 & $9,28 \div \div$ \\
\hline $\mathrm{EdP}_{4}$ & ${ }^{\circ}$ & 2 & 123922 & 61961 & $4,94 *$ \\
\hline $\mathrm{EdP}_{5}$ & & 2 & 177962 & 88981 & $7,10 \div$ \\
\hline $\mathrm{PdE}_{1}$ & & 4 & 95595 & 23898 & $1,86^{\mathrm{ns}}$ \\
\hline $\mathrm{PdE}_{2}$ & & 4 & 65087 & 16271 & $1,27^{\mathrm{ns}}$ \\
\hline $\mathrm{PdE}_{3}$ & & 4 & 24222 & 6055 & $0,47^{n s}$ \\
\hline Erro(b) & & 30 & 376115 & 12537 & - \\
\hline Total & & 59 & 1793991 & - & - \\
\hline
\end{tabular}

$1 E=$ época de plantio da brachiária. Niveis de significancia: $5 \%(\stackrel{\dot{*}}{*})$ e $1 \%(\stackrel{\dot{*}}{*})$

ns - não significativo a $5 \%$

C.V. $=48,45$ 
Tabela 23 - Anālise de variāncia para a brachiāria. Experimento A(07/10/81).

\begin{tabular}{|c|c|c|c|c|c|}
\hline $\begin{array}{l}\text { Causas de } \\
\text { variação }\end{array}$ & & G.L. & $S \cdot Q$. & Q.M. & F \\
\hline Blocos & & 3 & 101194006 & 33731335 & $7,82 \%$ \\
\hline $\mathrm{P}_{2} \mathrm{O}_{5}$ & & 4 & 52158712 & 13039678 & $3,02^{\mathrm{ns}}$ \\
\hline Erro(a) & & 12 & 51772542 & 4314378 & - \\
\hline Parcelas & . & 19 & 205125260 & - & - \\
\hline$E^{1}$ & & 2 & 700593688 & 350296844 & $42,03 * x$ \\
\hline ExP & & 8 & 152709672 & 19088709 & $2,29 *$ \\
\hline $\mathrm{EdP}_{1}$ & & 2 & 89809519 & 44904759 & $5,39 *$ \\
\hline $\mathrm{EdP}_{2}$ & & 2 & 193908159 & 96954079 & $11,63 * *$ \\
\hline $\mathrm{EdP}_{3}$ & $\because$ & 2 & 133199157 & 66599578 & $7,99 * *$ \\
\hline $\mathrm{EdP}_{4}$ & & 2 & 2268523015 & 134261507 & $16,11 * *$ \\
\hline $\mathrm{EdP}_{5}$ & & 2 & 2167863514 & 83931757 & $10,07 \div$ \\
\hline $\mathrm{PdE}_{1}$ & 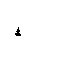 & 4 & 2244592 & 561148 & $0,08^{n s}$ \\
\hline $\mathrm{PdE}_{2}$ & & 4 & 193209256 & 48302314 & $6,91 * \pi$ \\
\hline $\mathrm{PdE}_{3}$ & & 4 & 9414533 & 2353633 & $0,34^{n s}$ \\
\hline Erro(b) & & 30 & 250013996 & 8333799 & - \\
\hline Total & & 59 & 591308442617 & - & - \\
\hline
\end{tabular}

$1 \mathrm{E}=$ época de plantio de brachiāria. Niveis de significância: $5 \%(*)$ e $1 \%(* *)$ ns - não significativo a $5 \%$ C.V. $=36,58$ 
Tabela 24 - Anālise de variância para a brachiāria. Experimento B(27/10/81).

\begin{tabular}{|c|c|c|c|c|c|}
\hline $\begin{array}{l}\text { Causas de } \\
\text { variação }\end{array}$ & & G.L. & $S \cdot Q$. & Q.M. & F \\
\hline Blocos & & 3 & 178293764 & 59431254 & $2,69^{\mathrm{ns}}$ \\
\hline $\mathrm{P}_{2} \mathrm{O}_{5}$ & & 4 & 244573476 & 61143369 & $2,77^{\mathrm{ns}}$ \\
\hline Erro(a) & & 12 & 264759276 & 22063273 & - \\
\hline Parcelas & $\cdot$ & 19 & 687626516 & - & - \\
\hline$E^{1}$ & & 2 & 148212130 & 74106065 & $4,51 \div$ \\
\hline ExP & & 8 & 53986746 & 6748343 & $0,41^{\mathrm{ns}}$ \\
\hline $\mathrm{EdP}_{1}$ & & 2 & 4574220 & 2287110 & $0,14^{\mathrm{ns}}$ \\
\hline $\mathrm{EdP}_{2}$ & $;$ & 2 & 12518526 & 6259263 & $0,38^{\mathrm{ns}}$ \\
\hline $\mathrm{EdP}_{3}$ & & 2 & 103347661 & 51673830 & $3,14^{\mathrm{ns}}$ \\
\hline $\mathrm{EdP}_{4}$ & & 2 & 25976746 & 12988373 & $0,79^{\mathrm{ns}}$ \\
\hline $\mathrm{EdP}_{5}$ & & 2 & 55781723 & 27890861 & $1,70^{\mathrm{ns}}$ \\
\hline $\mathrm{PdE}_{1}$ & & 4 & 96768799 & 24192199 & $1,32^{\mathrm{ns}}$ \\
\hline $\mathrm{PdE}_{2}$ & & 4 & 153754842 & 38438710 & $2,10^{\mathrm{ns}}$ \\
\hline $\mathrm{PdE}_{3}$ & & 4 & 48036579 & 12009144 & $0,66^{\mathrm{ns}}$ \\
\hline Erro(b) & & 30 & 493244140 & 16441471 & - \\
\hline Total & & 59 & 591383069533 & - & - \\
\hline
\end{tabular}

$I_{E}=$ época de plantio de brachiária Nível de significāncia: $5 \%(*)$ ns - não significativo a $5 \%$ C.V. $=60,20$ 
Tabela 25 - Análise de variāncia para a brachiária. Experimento $\mathrm{C}(16 / 11 / 81)$.

\begin{tabular}{|c|c|c|c|c|c|}
\hline $\begin{array}{l}\text { Causas de } \\
\text { variação }\end{array}$ & & G.L. & $S \cdot Q$. & Q.M. & $\mathrm{F}$ \\
\hline Blocos & & 3 & 9914754 & 3304918 & $0,76^{\mathrm{ns}}$ \\
\hline $\mathrm{P}_{2} \mathrm{O}_{5}$ & & 4 & 20586127 & 5146531 & $1,19^{\mathrm{ns}}$ \\
\hline Erro(a) & & 12 & 51918932 & 4326577 & - \\
\hline Parcelas & & 19 & 82419813 & - & - \\
\hline $\mathrm{E}^{2}$ & & 2 & 281792448 & 140896224 & $74,58 \div \frac{1}{\pi}$ \\
\hline $\operatorname{ExP}$ & & 8 & 25635383 & 3204422 & $1,70^{\mathrm{ns}}$ \\
\hline $\mathrm{EdP}_{1}$ & & 2 & 44921753 & 22460876 & $11,89 \div$ \\
\hline $\mathrm{EdP}_{2}$ & & 2 & 47488355 & 237441.77 & $12,57 \div \div$ \\
\hline $\mathrm{EdP}_{3}$ & & 2 & 77721845 & 38860922 & $20,57 \div \div$ \\
\hline $\mathrm{EdP}_{4}$ & $\ddot{z}$ & 2 & 21671376 & 10835688 & $5,74 \div \frac{1}{x}$ \\
\hline $\mathrm{EdP}_{5}$ & & 2 & 115624500 & 57812250 & $30,60 \div \frac{\pi}{\pi}$ \\
\hline $\mathrm{PdE}_{1}$ & & 4 & 17194224 & 4298556 & $1,59^{\mathrm{ns}}$ \\
\hline $\mathrm{PdE}_{2}$ & & 4 & 15827294 & 3956823 & $1,46^{\mathrm{ns}}$ \\
\hline $\mathrm{PdE}_{3}$ & & 4 & 13199988 & 3299997 & $1,22^{\mathrm{ns}}$ \\
\hline Erro(b) & & 30 & 56679080 & 1889302 & - \\
\hline Total & & 59 & 446526724 & - & - \\
\hline
\end{tabular}

$1 \mathrm{E}=$ época de plantio de brachiāria. Nivel de significância: 1\% ( ns - não significativo a $5 \%$ C.V. $=23,58$ 
.73.

Tabela 26. Estimativas dos parâmetros, seus respectivos desvios padrões, coe ficientes de determinação, valores de "t"l/ - Produção Arroz - Ré $^{-}$ lativos à equação $\hat{y}=a+b x+c x^{2}$

\begin{tabular}{|c|c|c|c|c|c|c|c|}
\hline \multirow{2}{*}{$\begin{array}{l}\text { Experi } \\
\text {-mento }\end{array}$} & \multicolumn{6}{|c|}{$\mathrm{E} s \mathrm{~s} i \mathrm{~m}$ a $i \mathrm{v}$ a $\mathrm{s}$} & \multirow{2}{*}{$\begin{array}{l}\text { Coeficien } \\
\text { te de De } \\
\text { terminaçâa }\end{array}$} \\
\hline & $\mathrm{a}$ & $s(a)$ & $\mathrm{b}$ & $s(b)$ & C & $s(c)$ & \\
\hline$A-p$ & $\begin{array}{r}1454,23 \\
(8,25)\end{array}$ & 176,09 & $\begin{array}{l}-48,32 \\
(-0,23)\end{array}$ & 208,59 & $\begin{array}{l}39,21 \\
(0,78)\end{array}$ & 50,00 & 3,67 \\
\hline$B-p$ & $\begin{array}{l}1846,39 \\
(13,56)\end{array}$ & 136,13 & $\begin{array}{l}-33,24 \\
(-0,20)\end{array}$ & 161,26 & $\begin{array}{c}5,42 \\
(0,14)\end{array}$ & 38,65 & 0,13 \\
\hline$c-p$ & $\begin{array}{l}313,10 \\
(10,16)\end{array}$ & 30,80 & $\begin{array}{l}-97,27 \\
(-2,66)\end{array}$ & 36,48 & $\begin{array}{l}18,75 \\
(2,14)\end{array}$ & 8,74 & 6,60 \\
\hline$A-a$ & $\begin{array}{l}688,23 \\
(2,25)\end{array}$ & 305,00 & $\begin{array}{c}323,76^{\mathrm{NS}} \\
(0,89)\end{array}$ & 361,29 & $\begin{array}{l}-56,34^{\mathrm{NS}} \\
(-0,65)\end{array}$ & 86,61 & 8,17 \\
\hline $\mathrm{B}-\mathrm{a}$ & $\begin{array}{c}1882,64 \\
(7,98)\end{array}$ & $\begin{array}{r}235,79 \\
\because\end{array}$ & $\begin{array}{r}-173,40 \\
(-0,62)\end{array}$ & $279 ; 31$ & $\begin{array}{l}35,69 \\
(0,533)\end{array}$ & 66,96 & 1,95 \\
\hline $\mathrm{C}-\mathrm{a}$ & $\begin{array}{l}231,57 \\
(4,34)\end{array}$ & 53,34 & $\begin{array}{r}-133,60 \\
(-2,11)\end{array}$ & 63,19 & $\begin{array}{l}23,79 \\
(1,57)\end{array}$ & 15,15 & 54,25 \\
\hline$\dot{\mathrm{A}}-\mathrm{b}$ & $\begin{array}{r}2026,27 \\
(6,643)\end{array}$ & 305,00 & $\begin{array}{l}-545,50 \\
(-1,509)\end{array}$ & 361,29 & $\begin{array}{r}1.44,05 \\
(1,66)\end{array}$ & 86,61 & 9,05 \\
\hline$B-b$ & $\begin{array}{r}1997,06 \\
(8,46)\end{array}$ & 235,79 & $\begin{array}{l}-111,67 \\
(-0,399)\end{array}$ & 279,31 & $\begin{array}{c}6,59 \\
(0,098)\end{array}$ & 66,96 & 4,25 \\
\hline $\mathrm{c}-\mathrm{b}$ & $\begin{array}{l}326,37 \\
(6,117)\end{array}$ & 53,34 & $\begin{array}{l}-124,66 \\
(-1,97)\end{array}$ & 63,19 & $\begin{array}{l}25,52 \\
(1,68)\end{array}$ & 15,15 & 18,06 \\
\hline$A-C$ & $\begin{array}{r}1648,19 \\
(5,403)\end{array}$ & 305,00 & $\begin{array}{c}76,77 \\
(0,212)\end{array}$ & 361,29 & $\begin{array}{l}29,92 \\
(0,345)\end{array}$ & 86,61 & 11,13 \\
\hline$B-C$ & $\begin{array}{r}1659,46 \\
(7,037)\end{array}$ & 235,79 & $\begin{array}{c}185,33^{N S} \\
(0,663)\end{array}$ & 279,31 & $\begin{array}{l}-26,00^{\mathrm{NS}} \\
(-0,388)\end{array}$ & 66,96 & 9,47 \\
\hline$c-c$ & $\begin{array}{l}381,36 \\
(7,148)\end{array}$ & 53,34 & $\begin{array}{l}-33,55 \\
(-0,53)\end{array}$ & 63,19 & $\begin{array}{c}6,94 \\
(0,458)\end{array}$ & 15,15 & 0,58 \\
\hline
\end{tabular}

1/ Os valores do teste "t" são apresentados entre parênteses NS. Não significativo a $10 \%$ 
.74 .

Tabela 27. Estimativas dos parâmetros, seus respectivos desvios padrōes, coeficientes de determinação e valores de " $t$ " 1/_ Produção Arroz - Relativos à equação $\hat{y}=a+b x+c \sqrt{x}$

Experi-

E $s \quad t \quad m a t$ i $v$ a

Coeficientes

mento

de Determina ção.

\begin{tabular}{|c|c|c|c|c|c|c|c|}
\hline & $\mathrm{a}$ & $s(a)$ & $\mathrm{b}$ & $s(b)$ & c & $s(c)$ & \\
\hline \multirow[t]{2}{*}{$A-P$} & 1361,50 & 186,11 & 84,59 & 204,10 & 50,58 & 412,79 & 3,12 \\
\hline & $(7,315)$ & & $(0,414)$ & & $(0,122)$ & & \\
\hline \multirow[t]{2}{*}{$B-p$} & 1795,09 & 143,88 & $-79,20^{\mathrm{NS}}$ & 157,78 & $142,99^{\mathrm{NS}}$ & 319,12 & 0,41 \\
\hline & $(12,476)$ & & $(-0,501)$ & & $(0,448)$ & & \\
\hline \multirow[t]{2}{*}{$c-p$} & 321,98 & 32,55 & 55,36 & 35,70 & $-164,01$ & 72,20 & 7,00 \\
\hline & $(9,890)$ & & $(1,550)$ & & $(-2,271)$ & & \\
\hline \multirow[t]{2}{*}{$A-a$} & 708,63 & 322,35 & $-56,01^{\mathrm{NS}}$ & 353,51 & $326,30^{\mathrm{NS}}$ & 714,98 & 6,86 \\
\hline & $(2,198)$ & & $(-0,158)$ & & $(\theta, 456)$ & & \\
\hline \multirow[t]{2}{*}{$B-a$} & 1853,84 & 249,20 & 40,64 & 273,29 & $-150,58$ & 552,74 & 1,00 \\
\hline & $(7,438)$ & & $(0,148)$ & & $(-0,272)$ & & \\
\hline \multirow[t]{2}{*}{$c-a$} & 241,97 & 56,38 & 58,60 & 61,83 & $-205,03$ & 125,05 & 55,94 \\
\hline & $(4,291)$ & & $(0,947)$ & & $(-1,639)$ & & \\
\hline \multirow[t]{2}{*}{$\mathrm{A}-\mathrm{b}$} & 1896,98 & 322,35 & 296,40 & 353,51 & $-561,49$ & 714,98 & 2,24 \\
\hline & $(5,88)$ & & $(0,838)$ & & $(-0,785)$ & & \\
\hline \multirow[t]{2}{*}{$B-b$} & 1949,54 & 249,20 & $-142,76^{\mathrm{NS}}$ & 273,29 & $121,40^{\mathrm{NS}}$ & 552,74 & 4,39 \\
\hline & $(7,822)$ & & $(-0,522)$ & & $(0,219)$ & & \\
\hline \multirow[t]{2}{*}{$c-b$} & 333,72 & 56,38 & 75,14 & 61,83 & $-206,48$ & 125,05 & 17,60 \\
\hline & $(5,918)$ & & $(1,215)$ & & $(-1,651)$ & & \\
\hline \multirow[t]{2}{*}{$A-c$} & 1478,89 & 322,35 & 13,38 & 353,51 & 386,93 & 714,93 & 11,64 \\
\hline & $(4,587)$ & & $(0,037)$ & & $(0,541)$ & & \\
\hline \multirow[t]{2}{*}{$B-c$} & 1581,88 & 249,20 & $-135,50^{\mathrm{NS}}$ & 273,29 & $458,17^{\mathrm{NS}}$ & 552,74 & 13,69 \\
\hline & $(6,347)$ & & $(-0,495)$ & & $(0,828)$ & & \\
\hline \multirow[t]{2}{*}{$C-c$} & 390,25 & 56,38 & 32,32 & 61,83 & $-80,54$ & 125,05 & 0,96 \\
\hline & $(6,921)$ & & $(0,522)$ & & $-0,644$ & & \\
\hline
\end{tabular}

$1 /$ Os valores do teste "t" são apresentados entre parênteses NS Não significativo a $10 \%$ 
Tabela 28. Estimativas dos parâmetros, seus respectivos desvios padrões e coeficientes de determinação e valores de "t" 1/ - Produção brachiaria - relativos a e quaçäo $\hat{\mathrm{y}}=\mathrm{a}+\mathrm{bx}+\mathrm{cx} \mathrm{x}^{2}$.

\begin{tabular}{|c|c|c|c|c|c|c|c|}
\hline \multirow[t]{2}{*}{ Experi } & \multicolumn{6}{|c|}{ Es $t i m a t i v a s$} & \multirow{2}{*}{$\begin{array}{l}\text { Coeficien } \\
\text { te de } D \epsilon \text { F } \\
\text { terminação }\end{array}$} \\
\hline & a & $s(a)$ & $\mathrm{b}$ & $s(b)$ & c & $s(c)$ & \\
\hline$A-p$ & $\begin{array}{l}6935,96 \\
(9,653)\end{array}$ & 718,48 & $\begin{array}{r}1046,59^{\mathrm{NS}} \\
(1,229)\end{array}$ & 851,10 & $\begin{array}{r}-189,83^{\mathrm{NS}} \\
(-0,930)\end{array}$ & $-204,03$ & 1,22 \\
\hline$B-p$ & $\begin{array}{r}3212,30 \\
\quad(2,762)\end{array}$ & 1162,69 & $\begin{array}{r}3255,94 \div \frac{1}{\star} \\
(2,364)\end{array}$ & 1377,29 & $\begin{array}{r}-498,01 * \\
(-1,508)\end{array}$ & 330,18 & 16,87 \\
\hline$c-p$ & $\begin{array}{l}4916,59 \\
(11,010)\end{array}$ & 446,55 & $\begin{array}{r}1114,14 \div * \\
(2,106)\end{array}$ & 528,98 & $\begin{array}{r}-219,11 * * \\
(-1,727)\end{array}$ & 126,81 & 3,32 \\
\hline$A-a$ & $\begin{array}{l}10564,25 \\
(8,489) .\end{array}$ & 1244,45 & $\begin{array}{r}263,13^{\mathrm{NS}} \\
(0,178)\end{array}$ & 1474,15 & $\begin{array}{r}-101,20^{\mathrm{NS}} \\
(-0,286)\end{array}$ & 353,40 & 4,06 \\
\hline$B-a$ & $\begin{array}{r}3971,43 \\
(1,972)\end{array}$ & $\begin{array}{c}2013,84 \\
:\end{array}$ & $\begin{array}{r}4319,63 \div \frac{1}{*} \\
(1,810)\end{array}$ & 2385,55 & $\begin{array}{r}-776,78 \div \\
(-1,358)\end{array}$ & 571,89 & 15,14 \\
\hline$c-a$ & $\begin{array}{l}6154,77 \\
(25,163)\end{array}$ & 244,58 & $\begin{array}{c}1232,13 \div \div \div \\
(4,252)\end{array}$ & 289,73 & $\begin{array}{c}-214,28 \div+\frac{1}{x} \\
(-3,085)\end{array}$ & 69,45 & 17,75 \\
\hline$A-b$ & $\begin{array}{r}5915,46 \\
(4,753)\end{array}$ & 1244,45 & $\begin{array}{c}4256,55 \div \div \frac{1}{*} \\
(2,887)\end{array}$ & 1474,15 & $\begin{array}{c}-717,26 * * \\
(-2,029)\end{array}$ & 353,40 & 21,42 \\
\hline$B-b$ & $\begin{array}{r}2998,82 \\
(1,489)\end{array}$ & 2013,84 & $\begin{array}{r}3960,69 * \\
(1,660)\end{array}$ & 2385,55 & $\begin{array}{r}-529,75^{\mathrm{NS}} \\
(-0,926)\end{array}$ & 571,89 & 31,60 \\
\hline$c-b$ & $\begin{array}{r}6615,48 \\
(8,553)\end{array}$ & 773,45 & $\begin{array}{c}539,88^{\mathrm{NS}} \\
(0,589)\end{array}$ & 916,22 & $\begin{array}{l}-50,59^{\mathrm{NS}} \\
(-0,230)\end{array}$ & 219,64 & 7,37 \\
\hline$A-C$ & $\begin{array}{r}4328,18 \\
(3,477)\end{array}$ & 1244,45 & $\begin{array}{r}-1379,90 \\
(-0,936)\end{array}$ & 1474,15 & $\begin{array}{l}248,94 \\
(0,704)\end{array}$ & 353,40 & 11,70 \\
\hline$B-c$ & $\begin{array}{r}2666,66 \\
(1,324)\end{array}$ & 2013,84 & $\begin{array}{c}1487,48^{N S} \\
(0,623)\end{array}$ & 2385,55 & $\begin{array}{r}-187,49^{\mathrm{NS}} \\
(-0,327)\end{array}$ & 571,89 & 16,43 \\
\hline$C-C$ & $\begin{array}{r}1979,52 \\
(2,559)\end{array}$ & 773,45 & $\begin{array}{c}1570,41 * * \\
(1,714)\end{array}$ & 916,22 & $\begin{array}{c}-392,46 * * \\
(-1,786)\end{array}$ & 219,64 & 15,73 \\
\hline
\end{tabular}

$1 /$ - Os valores do teste "t" são apresentados entre parênteses Níveis de significância $1 \%(\dot{*} * \dot{*}), 5 \%(\stackrel{*}{*})$ e $10 \%\left(\frac{\dot{*}}{*}\right)$ 
Tabela 29. Estimativas dos parâmetros, seus respectivos desvios padrões, coeficientes de determinação e valores de "t" 1/ - Produção Brachiaria -Relativos à equaçāo : $\hat{\mathrm{y}}=\mathrm{a}+\mathrm{bx}+\mathrm{c} \sqrt{\mathrm{x}}$

\begin{tabular}{|c|c|c|c|c|c|c|c|}
\hline \multirow{2}{*}{$\begin{array}{l}\text { Experi } \\
\text { mento }\end{array}$} & \multicolumn{6}{|c|}{ E s t ima $t i v a s$} & \multirow{2}{*}{$\begin{array}{l}\text { Coefici } \\
\text { ente de } \\
\text { Determi } \\
\text { naçāo }\end{array}$} \\
\hline & $a$ & $s(a)$ & $b$ & $s(b)$ & c & $s(c)$ & \\
\hline$A-p$ & $\begin{array}{l}6694,05 \\
(8,815)\end{array}$ & 759,36 & $\begin{array}{r}-752,70^{\mathrm{NS}} \\
(-0,903)\end{array}$ & 832,76 & $\begin{array}{r}2197,66 * \\
(1,304)\end{array}$ & 1684,27 & 1,67 \\
\hline $\mathrm{B}-\mathrm{p}$ & $\begin{array}{r}2919,52 \\
(2,375)\end{array}$ & 1228,84 & $\begin{array}{r}-892,32^{\mathrm{NS}} \\
(-0,662)\end{array}$ & 1347,62 & $\begin{array}{r}4556,61 * \\
(1,671)\end{array}$ & 2725,57 & 17,56 \\
\hline$C-p$ & $\begin{array}{l}4894,38 \\
(10,370)\end{array}$ & 471,96 & $\begin{array}{r}-532,64^{\mathrm{NS}} \\
(-1,029)\end{array}$ & 517,58 & $\begin{array}{r}1627,88 * \\
(1,555)\end{array}$ & 1046,81 & 2,98 \\
\hline$A-a$ & $\begin{array}{r}10477,71 \\
(7,966)\end{array}$ & . 1315,26 & $\begin{array}{c}-625,07^{\mathrm{NS}} \\
(-0,433)\end{array}$ & 1442,39 & $\begin{array}{r}1021,56^{\mathrm{NS}} \\
(0,350)\end{array}$ & 2917,24 & 4,90 \\
\hline $\mathrm{B}-\mathrm{a}$ & $\begin{array}{r}3656,93 \\
(1,718)\end{array}$ & 2128,42 & $\begin{array}{c}-1912,85^{\mathrm{NS}} \\
(-0,819)\end{array}$ & 2334,15 & $\begin{array}{r}6604,63 * \\
(1,399)\end{array}$ & 4720,83 & 15,48 \\
\hline$C-a$ & $\begin{array}{l}6201,14 \\
(23,988)\end{array}$ & 258,50 & $\begin{array}{c}-264,41^{\mathrm{NS}} \\
(-0,932)\end{array}$ & 283,49 & $\begin{array}{c}1351,24 * * \\
(2,356)\end{array}$ & 573,36 & 15,43 \\
\hline $\mathrm{A}-\mathrm{b}$ & $\begin{array}{l}52,34,19 \\
\quad(3,979)\end{array}$ & 1315,26 & $\begin{array}{c}-2152,28 * \\
(-1,492)\end{array}$ & 1442,39 & $\begin{array}{c}7480,46 * * * \\
(2,564)\end{array}$ & 2917,24 & 24.90 \\
\hline$B-b$ & $\begin{array}{l}2764,11 \\
\quad(1,298)\end{array}$ & 2128,42 & $\begin{array}{c}-323,61^{\mathrm{NS}} \\
(-0,138)\end{array}$ & 2334,15 & $\begin{array}{r}4575,77^{\mathrm{NS}} \\
(0,969)\end{array}$ & 4720,83 & 31,91 \\
\hline$c-b$ & $\begin{array}{r}6383,68 \\
(7,809)\end{array}$ & 817,46 & $\begin{array}{l}-219,62^{\mathrm{NS}} \\
(-0,244)\end{array}$ & 896,48 & $\begin{array}{r}1177,31^{N S} \\
(0,649)\end{array}$ & 1813,13 & 8,93 \\
\hline$A-C$ & $\begin{array}{r}4370,24 \\
(3,322)\end{array}$ & 1315,26 & $\begin{array}{l}519,24 \\
(0,359)\end{array}$ & 1442,39 & $\begin{array}{r}-1909,04 \\
(-0,654)\end{array}$ & 2917,24 & 11,10 \\
\hline$B-c$ & $\begin{array}{r}2337,52 \\
(1,098)\end{array}$ & 2128,42 & $\begin{array}{l}-440,50^{\mathrm{NS}} \\
(-0,188)\end{array}$ & 2334,15 & $\begin{array}{r}2489,44^{\mathrm{NS}} \\
(0,527)\end{array}$ & 4720,83 & 18,59 \\
\hline$C-c$ & $\begin{array}{r}2098,32 \\
(2,566)\end{array}$ & 817,46 & $\begin{array}{c}-1113,88^{\mathrm{NS}} \\
(-1,242)\end{array}$ & 896,48 & $\begin{array}{r}2355,09^{\mathrm{NS}} \\
(1,298)\end{array}$ & 1813,13 & 8,31 \\
\hline
\end{tabular}

$1 /$ Os valores do teste " $t$ " são apresentados entre parênteses Níveis de significância: $1 \%(* * *), 5 \%(* *)$ e $10 \%(*)$. 
Tabela $30^{\circ}$ - Estimativas dos parâmetros das variáveis blocos, fósforo e época de plantio da brachiária, ajustados aos dados do experimento A da produção de arroz.

\begin{tabular}{lcc}
\hline Variäveis & $\begin{array}{c}\text { Estimativa do } \\
\text { parämetro }\end{array}$ & Teste " $t^{\text {II }}$ \\
\hline $\mathrm{B}_{1}=2$ 9 bloco & $-871,77$ & $-3,294^{* * *}$ \\
$\mathrm{~B}_{2}=3$ 9 bloco & $-334,11$ & $-1,262^{\mathrm{ns}}$ \\
$\mathrm{B}_{3}=$ 49 bloco & $-450,43$ & $-1,702^{\mathrm{ns}}$ \\
$\mathrm{P}=$ fósforo & $-97,36$ & $-0,394$ \\
$\mathrm{E}=$ época & 1013,84 & $2,284^{*}$ \\
$\mathrm{P}^{2}$ & 39,21 & 0,701 \\
$\mathrm{E}^{2}$ & $-310,06$ & $-1,562^{\mathrm{ns}}$ \\
$\mathrm{PxE}$ & 49,04 & $0,605^{\mathrm{ns}}$ \\
\hline
\end{tabular}

$\mathrm{R}^{2} \%(41,04) \quad \because$

ns - não significativo ao nivel de $5 \%$

I niveis de significāncia $1 \%(\dot{*} *)$ e $5 \%(*)$ 
Tabela $31^{\circ}$ - Estimativas dos parāmetros das variäveis blocos, fósforo e època de plantio da brachiária, ajustados aos dados do experimento B da produção de arroz.

\begin{tabular}{|c|c|c|}
\hline Variāveis & $\begin{array}{c}\text { Estimativa do } \\
\text { parāmetro }\end{array}$ & Teste "t"I \\
\hline $\mathrm{B}_{I}=2 \mathrm{O}$ bloco & $-289,73$ & $-1,636^{\mathrm{ns}}$ \\
\hline $\mathrm{B}_{2}=39$ bloco & 239,78 & $1,354^{\mathrm{ns}}$ \\
\hline $\mathrm{B}_{3}=4 \mathrm{Q}$ bloco & 322,04 & $1,818^{\mathrm{ns}}$ \\
\hline$P=$ fósforo & $-89,20$ & $-0,539$ \\
\hline$E^{\prime}=$ época & $-47,48$ & $-0,159$ \\
\hline $\mathrm{P}^{2}$ & 5,42 & 0,145 \\
\hline$E^{2}$ & $-\quad 1,20$ & $-0,009^{\mathrm{ns}}$ \\
\hline $\operatorname{ExP}$ & 55,95 & $1,032^{n s}$ \\
\hline
\end{tabular}

$\mathrm{R}^{2} \%(24,18)$

1 não significativo ao nivel de $5 \%$ 
Tabela 32 - Estimativas dus parāmetros das variāveis blocos, fósforo e època de plantio de brachiāria, ajustados aos dados do experimento C da produção de arroz.

Variāveis

Estimativa do

Teste " $t$ "I

parāmetro

\begin{tabular}{lrc}
\hline $\mathrm{B}_{1}=2$ 9 bloco & $-119,80$ & $-3,068 * *$ \\
$\mathrm{~B}_{2}=3$ 9 bloco & 96,97 & $2,483 *$ \\
$\mathrm{~B}_{3}=4$ 9 bloco & 86,00 & $2,202 *$ \\
$\mathrm{P}=$ fósforo & $-113,59$ & $-3,118$ \\
$\mathrm{E}=$ época & 89,08 & $1,360^{\mathrm{ns}}$ \\
$\mathrm{P}^{2}$ & 18,75 & 2,273 \\
$\mathrm{E}^{2}$ & 1,33 & 0,045 \\
$\mathrm{PxE}$ & 16,31 & $1,364^{\mathrm{ns}}$ \\
\hline
\end{tabular}

$\mathrm{R}^{2} \%(67,50)$

I não significativo ao nivel de 5\% Niveis de significância $1 \%(* *)$ e $5 \%(*)$ 
Tabela 33- Estimativas dos parâmetros das variäveis blocos, fósforo e época de plantio da brachiäria ajustados aos dados do experi mento A da produção de brachiāria.

Variāveis

Estimativa do

parāmetro

Teste " $t " 1$

$\mathrm{B}_{1}=29$ bloco
$\mathrm{B}_{2}=3$ ! bloco
$\mathrm{B}_{3}=4$ ! bloco
$\mathrm{P}=$ fösforo
$\mathrm{E}=$ época
$\dot{\mathrm{P}}^{2}$
$\mathrm{E}^{2}$

1777,78

$1,571^{\text {ns }}$

$-1617,27$

$-1,429^{\mathrm{ns}}$

$-1088,87$

$-0,962^{\mathrm{ns}}$

1167,82

$1,106^{\text {ns }}$

3236,45

$1,705 *$

$-189,83$

$-0,794^{\mathrm{nS}}$

$-3352,31$

$-3,950 * *$

PxE

$-121,22$

$-0,349^{\mathrm{ns}}$

$\mathrm{R}^{2} \%(62,58)$

1 não significativo ao nivel de $5 \%$

Niveis de significāncia $1 \%(* *)$ e $5 \%(*)$ 
Tabela 34 - Estimativas dos parâmetros das variāveis blocos, fósforo e época de plantio da brachiária, ajustados aos dados do experimento $B$ da produção de brachiária.

\begin{tabular}{|c|c|c|}
\hline Variāveis & $\begin{array}{c}\text { Estimativa do } \\
\text { parāmetro }\end{array}$ & Teste " $t$ "1 \\
\hline$B_{I}=20$ bloco & $-688,90$ & $-0,470^{n s}$ \\
\hline $\mathrm{B}_{2}=39$ bloco & $-4344,44$ & $-2,969 \div *$ \\
\hline $\mathrm{B}_{3}=4 \mathrm{9}$ bloco & $-2822,23$ & $-1,929^{n S}$ \\
\hline$P=$ fósforo & 3493,43 & $2,559 \div *$ \\
\hline$E=\overline{e p o c a}$ & 1774,98 & $0,723^{\mathrm{ns}}$ \\
\hline $\mathrm{P}^{2}$ & $-498,01$ & $-1,611^{\mathrm{ns}}$ \\
\hline$E^{2}$ & $-1508,33$ & $-1,374^{n s}$ \\
\hline $\operatorname{PxE}$ & $-237,49$ & $-0,530^{\mathrm{ns}}$ \\
\hline
\end{tabular}

$\mathrm{R}^{2} \%(40,80)$

1 não significativo ao nivel de $5 \%$

Nivel de significāncia $1 \%(* *)$ 
Tabela 35 - Estimativas dos parāmetros das variáveis blocos, fósforo e época de plantio da brachiária, ajustados aos dados do experimento C da produção de brachiária.

Variäveis

$\mathrm{B}_{1}=29$ bloco
$\mathrm{B}_{2}=39$ bloco
$\mathrm{B}_{3}=49$ bloco
$\mathrm{P}=$ fösforo
$\mathrm{E}=$ ëpoca
$\mathrm{P}^{2}$
$\mathrm{E}^{2}$
$\mathrm{PxE}$

Estimativa do

parāmetro
Teste "t"1

- 588,89

- 157,03

$-1044,45$

1301,36

2775, 00

$-219,11$

$-2342,22$

$-187,22$ $-0,983^{n s}$

$-0,262^{n s}$

$-1,744^{n s}$

$2,329 *$

$2,763 * x$

$-1,731 *$

$-5,214 * *$

$-1,021^{n s}$

$R^{2} \%(69,28)$

1 não significativo ao nivel de $5 \%$ Niveis de significância $1 \%(\stackrel{*}{*})$ e $5 \%(\stackrel{*}{*})$ 